\title{
On the Capability of Nonmetallic Inclusions to Act as Nuclei for Acicular Ferrite in Different Steel Grades
}

\author{
DENISE LODER, SUSANNE KATHARINA MICHELIC, \\ ALEXANDER MAYERHOFER, and CHRISTIAN BERNHARD
}

\begin{abstract}
Acicular ferrite nucleates intragranularly on nonmetallic inclusions, forming a microstructure with excellent fracture toughness. The formation of acicular ferrite is strongly affected by the size, content, and composition of nonmetallic inclusions, but also by the composition of the steel matrix. The potential of inclusions in medium carbon HSLA (high-strength low-alloyed) steels has been the main focus in the literature so far. The current study evaluates the acicular ferrite capability of various inclusions types in four different steel grades with carbon contents varying between 0.04 and $0.65 \mathrm{wt}$ pct. The investigated steels are produced by melting experiments on a laboratory scale and subsequent heat treatment in a High-Temperature Laser Scanning Confocal Microscope. Inclusions are exclusively formed by deoxidation and desulfurization reactions. No synthetic particles are added to the melt. The inclusion landscape is analyzed by Scanning Electron Microscopy. Final ductility of the samples is evaluated based on performed tensile tests. Inclusion types in every steel grade are assessed regarding their nucleation potential always considering the interaction with the steel composition, especially focusing on the role of manganese. The effects of $(\mathrm{Ti}, \mathrm{Al}) \mathrm{O}_{\mathrm{x}^{-}}, \mathrm{MnS}-$, and $\mathrm{MgO}$-containing inclusions are discussed in detail.
\end{abstract}

DOI: $10.1007 / \mathrm{s} 11663-017-0984-\mathrm{y}$

(C) The Minerals, Metals \& Materials Society and ASM International 2017

\section{INTRODUCTION}

The term 'steel cleanness' describes the number, size, chemical composition, and morphology of nonmetallic inclusions distributed in the steel matrix. Over many decades, intensive research on the improvement of steel cleanness, focusing on the reductions of inclusion size and frequency, has been performed. However, despite these efforts, the presence of nonmetallic inclusions in the steel matrix cannot be avoided completely. In general, nonmetallic inclusions are seen to negatively affect steel properties, such as ductility, fatigue strength and corrosion resistance. ${ }^{[1,2]}$ Murakami, ${ }^{[3]}$ for example, performed exhaustive work to describe the effect of nonmetallic inclusions on fatigue strength evaluating different influencing factors like inclusion shape and size, adhesion of inclusions to the matrix, and elastic constants of inclusion and matrix. However, specifically tailored inclusions can also be used for the creation of a favorable microstructure with enhanced properties. At the beginning of the 1990s, Takamura and Mizoguchi ${ }^{[4]}$

DENISE LODER, SUSANNE KATHARINA MICHELIC, ALEXANDER MAYERHOFER, and CHRISTIAN BERNHARD are with the Chair of Ferrous Metallurgy, Montanuniversitaet Leoben, 8700 Leoben, Austria. Contact e-mail: susanne.michelic@unileoben. ac.at

Manuscript submitted December 21, 2016.

Article published online May 4, 2017. introduced the concept of Oxides Metallurgy, which focuses on the use of inclusions to improve the final product quality - predominantly steel toughness - by controlling the inclusions' nature and distribution and thereby influencing the microstructure. Nonmetallic inclusions are described as the major cause for the nucleation of the high-toughness phase acicular ferrite. ${ }^{[5,6]}$

Acicular ferrite nucleates intragranularly on nonmetallic inclusions. The formed plates radiate in various directions and form a fine-grained, interlocking microstructure. ${ }^{[7]}$ Due to the chaotic arrangement of acicular ferrite grains, mechanical properties, especially fracture toughness, are significantly increased. This effect was first observed for weld metals. ${ }^{[8]}$ Comprehensive reviews on the formation of acicular ferrite have been done by Bhadeshia ${ }^{[9]}$ as well as Sarma et al.$^{[10]} \mathrm{Up}$ to now, $\mathrm{C}-\mathrm{Mn}-(\mathrm{Ni})$ weld metals ${ }^{[1-15]}$ were the most investigated material related to the formation of acicular ferrite.

The nucleation of acicular ferrite is mainly influenced by the steel composition, cooling rate, prior austenite grain size, and inclusion landscape. In the recent decades, considerable research has been conducted to evaluate different inclusion types regarding their capability for acicular ferrite: Ti-containing inclusions such as $\mathrm{TiN}$ and $\mathrm{TiC}^{[16]}$ titanium oxides ${ }^{[17-20]}$ partly in combination with rare earth metals, ${ }^{[17]}$ or Manganese ${ }^{[19]}$ have been intensively studied. The effects of many inclusion types have already been well described in the 
literature, with some popular types, however, being left out, with conflicting results. Apart from weld metals, most published studies addressed High-Strength LowAlloyed (HSLA) steels. ${ }^{[21-23]}$ Therefore, a systematic comparison of the inclusions' effects in different steel grades has been sparsely represented. Therefore, the current study compares four steel grades with significantly different compositions, and their effects on the capability of inclusions to nucleate acicular ferrite.

With regard to industrial processes and the requirements for modern, high-quality steels, the current study only uses endogenous inclusions as nuclei for acicular ferrite, avoiding an artificial increase of the inclusion content. $\mathrm{Mu}$ et $a .^{[21]}$ and Xuan et al. ${ }^{[22]}$ investigated different steel grades with carbon contents between 0.2 and 0.3 wt pct. They mostly used artificially added oxide powders like $\mathrm{Ti}_{2} \mathrm{O}_{3}$ to create the desired inclusion types because an appropriate tailoring of potent nucleation sites only by deoxidation and desulfurization reactions can be difficult. ${ }^{[2-23]}$ However, this might be in contrast to the demands of high-quality steels, which generally require low inclusion contents. The present study investigates the acicular ferrite formation on nonmetallic inclusions on a laboratory scale, with special consideration paid to the importance of the relationship between steel composition and inclusion type. Finally, material tests are conducted on the laboratory specimens to demonstrate the benefits of a microstructure containing acicular ferrite.

\section{EXPERIMENTAL PROCEDURE}

\section{A. Investigated Steel Grades}

Four steel grades (A-D) with carbon contents between 0.04 and 0.65 wt pet were investigated. Steel A reflected a typical HSLA steel composition, which has been widely applied in acicular ferrite investigations. Steels B to D represent compositions which might also be interesting for acicular ferrite microstructures but have hardly been treated in the literature up to now. For steels A and C, modifications in the chemical composition were tested; the variations of these steels were named A1-A3 and $\mathrm{C} 1-\mathrm{C} 2$, respectively. $\mathrm{A} 2$ is characterized through a significantly lower $\mathrm{Mn}$ content, and $\mathrm{Mg}$ contents in the order of a few parts per million are present in A3 as a result of reactions with the used crucible material. In contrast to $\mathrm{C} 1, \mathrm{C} 2$ contains no Titanium. The compositions of the investigated steels were determined by single spark spectroscopy and LECO measurements after casting. The compositions are given in Table I. These steel grades have already been previously investigated with regard to their acicular ferrite potential focusing on the influence of the carbon content. ${ }^{[24]}$

\section{B. Melting and Alloying Experiments in a Tammann-Type Furnace}

Melting experiments on a laboratory scale were performed in a Tammann-type furnace (Ruhrstrat HRTK 32 Sond.). Due to the carbon-heating tubes inside the furnace and their reaction with the residual oxygen, the final oxygen content in the furnace vessel is extremely low $(0.001 \mathrm{ppm})$. All experiments are conducted under an inert gas atmosphere. The weights of the produced melt samples were approximately $300 \mathrm{~g}$. A detailed description of the used Tammann-type furnace and raw materials can be found in References 25 and 26. Thermodynamic calculations were used to predict inclusion formation and modification and to set the necessary parameters for the melting experiments. For this purpose, FactSage 6.4 with the databases FactPS, FToxid, and FSstel was used. The calculations consisted of three steps:

a. Inclusion diagrams were calculated to determine the necessary steel composition for creating a particular inclusion landscape in the melt. Within the inclusion diagrams, two elements can be varied, and the effect of this variation on the inclusion landscape at a defined temperature is illustrated by the module Phasediagram of FactSage. However, inclusion diagrams do not model reactions during the experiment satisfactorily.

b. Reactions during the Tammann-type Furnace experiment were considered through further thermodynamic calculations using the Equilib module. In the current study, reactions with the crucible material, the stepwise addition of alloying elements, flotation of the inclusions during the experiment, as well as the influence of a preexisting inclusion landscape in the raw material are considered.

c. Finally, the change of inclusion landscape during cooling is calculated also using the Equilib module of FactSage. The inclusion formation during solidification has subsequently also been coupled with microsegregation calculations using ChemApp.

Although these calculations are a valuable basis to study reactions and interactions during the experiment, it has to be noted that FactSage only considers equilibrium conditions and no kinetic aspects. Thus, predicted inclusion types partly differ from inclusions detected in the SEM/EDS analyses. A detailed discussion of the calculation results, as well as a comparison between the calculated and experimental results, has been presented elsewhere. ${ }^{[25,27]}$

The experimental procedure in the Tammann-type furnace can be summarized as

a. Charging the unalloyed steel (Fe with 0.004 wt pct $\mathrm{C}$, 0.001 wt pet $\mathrm{Si}, 0.07$ wt pet $\mathrm{Mn}, 0.008$ wt pet $\mathrm{Al}$, 0.006 wt pet S, 0.004 wt pet $\mathrm{O}, 0.001$ wt pet N) and an oxygen-rich premelt in an $\mathrm{Al}_{2} \mathrm{O}_{3}$ crucible (exception steel A3: $\mathrm{MgO}$ crucible) using an elevator system that allows for the quick removal of the sample from the heat zone after the experiment.

b. Heating the material at $10 \mathrm{~K} / \mathrm{min}$, resulting in a melt with defined initial oxygen and sulfur contents.

c. Holding the melt for $19 \mathrm{~min}$ at the experimental temperature of $1873 \mathrm{~K}\left(1600^{\circ} \mathrm{C}\right)$, and adding the alloying elements $\mathrm{C}, \mathrm{Mn}$, and $\mathrm{Ti}$ as well as $\mathrm{Si}$ for samples C and D. Carrying out alloying using C-granules, electrolytic Mn, FeTi75, and FeSi75.

d. Achieving the formation of nonmetallic inclusions as a result of deoxidation and desulfurization, without the addition of synthetic particle powders. 
e. Stirring the melt in regular time steps to ensure a homogenous distribution of inclusions, using an $\mathrm{Al}_{2} \mathrm{O}_{3}$ rod.

f. Rapidly quenching the sample to prevent floatation of the inclusions during solidification.

\section{Heat Treatment in the HT-LSCM}

Samples produced in the Tammann-type Furnace were subsequently heat treated in the High-Temperature Laser Scanning Confocal Microscope (HT-LSCM). This method enables the in situ observation of nucleation and growth of acicular ferrite plates at high temperatures. Figure 1 demonstrates the sample preparation procedure based on the cast sample. Two slices were cut out of the cast sample. One slice was prepared metallographically and used for SEM/EDS analyses. From the second slice, specimens for subsequent HT-LSCM experiments were cut.

The HT-LSCM consisted of a VL2000DX laser scanning confocal microscope, produced by Lasertec, and an attached SVF17-SP high-temperature furnace, and the associated hardware and software from Yonekura. A comprehensive overview on the possibilities of HT-LSCM is given by Sridhar. ${ }^{[28]}$ The standard heat-treatment cycle for the current study is illustrated in Figure 2. The austenitization temperature $\left(T_{\text {aust }}\right)$, austenitization time ( $\left.t_{\text {aust }}\right)$, and cooling rate between $1073 \mathrm{~K}$ and $773 \mathrm{~K}\left(800^{\circ} \mathrm{C}\right.$ and $\left.500{ }^{\circ} \mathrm{C}\right)(\mathrm{CR}$ 8/5) are given in Table II. If an adjustment of the heat-treatment parameters was performed, the different heat treatments were labeled with hyphenated numbers at the end of the sample identification (e.g., A1-1).

\section{Metallographic Analyses}

The samples were analyzed metallographically with respect to the austenite grain size, acicular ferrite amount, and inclusion landscape, utilizing modern, computer-based analytic techniques:

a. The determination of the prior austenite grain size and the amount of acicular ferrite in the final microstructure were conducted by computerized routines using the image analysis software Clemex Vision 7.0. The routines calculated the austenite grain size distribution, and the fraction of acicular ferrite based on images captured by an optical Polyvar Pol microscope combined with a digital camera Clemex 4 megapixel. Detailed information on the evaluation routines and the necessary sample preparation was published previously by the authors. ${ }^{[29]}$

b. Inclusion characterization was performed by manual and automated SEM/EDS measurements. For these purposes, the samples were cut, embedded, and mechanically polished. The SEM/EDS measurements were performed using an FEI Quanta 200 MK2 scanning electron microscope (SEM), which was equipped with an energy dispersive X-ray spectrometer (EDS) system from Oxford Instruments. Inclusions are detected due to a difference in gray scale value in the backscattered electron image compared with the steel matrix. The applied settings for the automated SEM/EDS analyses are summarized in Table III. Further details of the SEM/EDS analyses' functions and applications can be found elsewhere. ${ }^{[30,31]}$

c. Heterogeneous nucleation played an important role during the cooling of the investigated steels. Many of

Table I. Steel Compositions of Investigated Samples

\begin{tabular}{|c|c|c|c|c|c|c|c|c|c|c|}
\hline \multirow[b]{2}{*}{ Steel } & \multicolumn{7}{|c|}{ (Wt Pct) } & \multicolumn{3}{|c|}{ (Wt Ppm) } \\
\hline & $\mathrm{C}$ & $\mathrm{Mn}$ & $\mathrm{Si}$ & $\mathrm{Al}$ & $\mathrm{Ti}$ & $\mathrm{Nb}$ & $\mathrm{Mg}$ & $\mathrm{O}$ & $\mathrm{S}$ & $\mathrm{N}$ \\
\hline $\mathrm{A} 1$ & 0.23 & 1.48 & 0.02 & 0.01 & 0.05 & 0.00 & - & 71 & 74 & 51 \\
\hline A 2 & 0.21 & 0.07 & 0.02 & 0.01 & 0.04 & 0.00 & - & 80 & 69 & 47 \\
\hline A3 & 0.24 & 1.41 & 0.02 & 0.01 & 0.05 & 0.00 & $<10$ & 61 & 60 & 39 \\
\hline B & 0.04 & 1.92 & 0.15 & 0.01 & 0.02 & 0.06 & - & 12 & 65 & 15 \\
\hline $\mathrm{C} 1$ & 0.24 & 1.91 & 1.80 & 0.00 & 0.03 & 0.00 & - & 22 & 59 & 39 \\
\hline $\mathrm{C} 2$ & 0.26 & 2.07 & 1.84 & 0.00 & 0.00 & 0.00 & - & 33 & 52 & 22 \\
\hline $\mathrm{D}$ & 0.65 & 0.97 & 0.49 & 0.01 & 0.05 & 0.00 & - & 14 & 63 & 22 \\
\hline
\end{tabular}

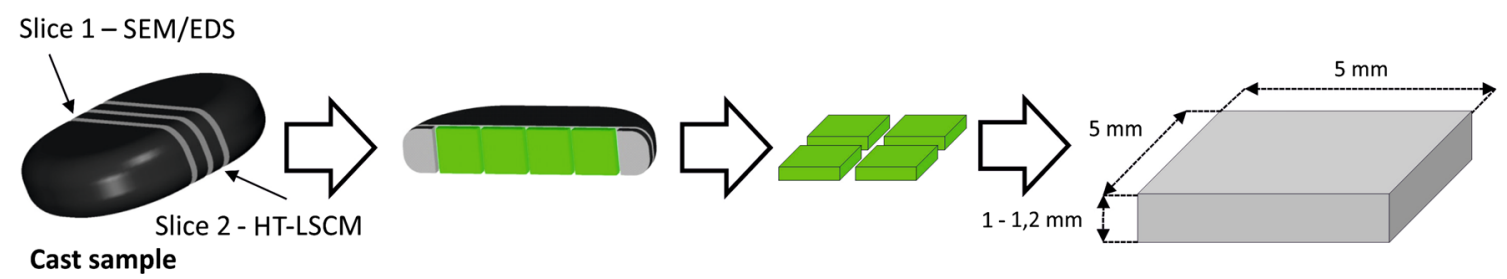

Fig. 1-Sample history for heat-treatment experiments in the HT-LSCM. 
the particles detected by SEM/EDS were multiphase inclusions. However, automated SEM/EDS only displayed the overall composition of an inclusion (measurement of total particle area). Hence, it was not possible to differ between single- and multiphase particles by automated SEM/EDS analysis. Information about the structure of heterogeneous particle and the chemical composition of its individual phases was only gained by manual measurements. Therefore, the current study uses a simplified inclusion-type nomenclature for the evaluation of automated SEM/EDS

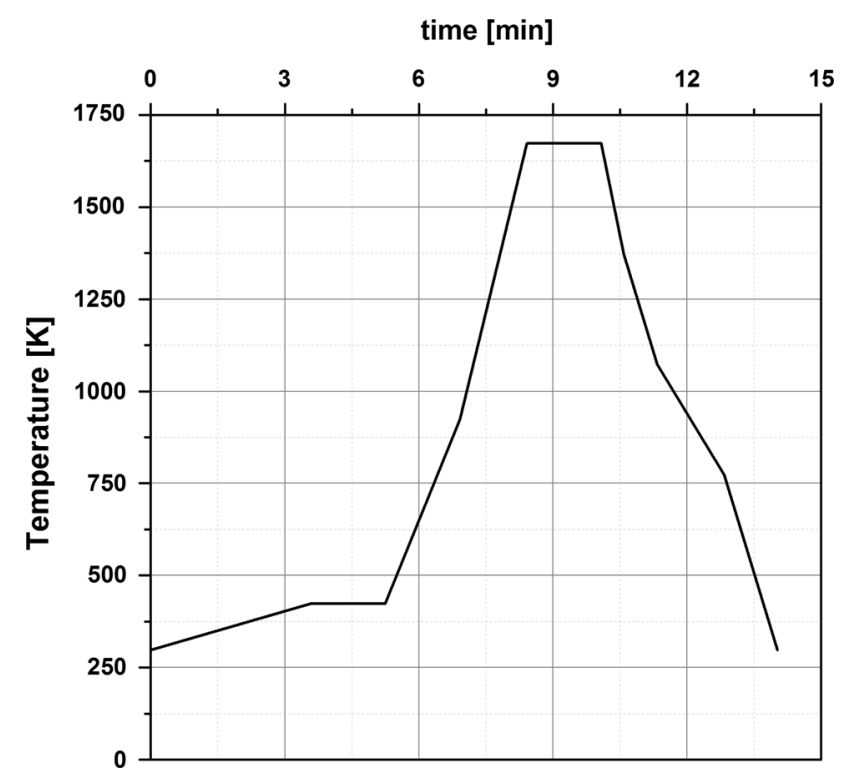

Fig. 2-Standard temperature cycle of HT-LSCM experiments.

Table II. Heat-Treatment Parameters

\begin{tabular}{lccc}
\hline Sample & $T_{\text {aust }}(\mathrm{K})\left({ }^{\circ} \mathrm{C}\right)$ & $t_{\text {aust }}(\mathrm{s})$ & $\mathrm{CR}_{8 / 5}\left[\mathrm{~K}\left({ }^{\circ} \mathrm{C}\right) / \mathrm{min}\right]$ \\
\hline A1-1 & $1673(1400)$ & 100 & -200 \\
A2-1 & $1673(1400)$ & 100 & -200 \\
A2-2 & $1673(1400)$ & 100 & -100 \\
A2-3 & $1673(1400)$ & 500 & -200 \\
A3-1 & $1673(1400)$ & 100 & -200 \\
B-1 & $1623(1350)$ & 100 & -200 \\
C1-1 & $1573(1300)$ & 100 & -200 \\
C1-2 & $1573(1300)$ & 300 & -100 \\
C2-1 & $1573(1300)$ & 300 & -200 \\
C2-2 & $1573(1300)$ & 300 & -20 \\
D-1 & $1573(1300)$ & 100 & -200 \\
\hline
\end{tabular}

Table III. Settings of Automated SEM/EDS Analyses

\begin{tabular}{ll}
\hline Accelerating voltage & $15 \mathrm{kV}$ \\
Working distance detector & $10 \mathrm{~mm}$ \\
Resolution & $1024 \times 960 \mathrm{px}$ \\
Magnification & 600 times \\
Minimum analyzed particle size & $4 \mathrm{px}=1.1 \mu \mathrm{m}$ \\
EDS measurement time & $3 \mathrm{~s} /$ particle \\
EDS measurement area & Total particle area \\
\hline
\end{tabular}

results. With this nomenclature, which only considers inclusion chemistry but not morphology, a reasonable evaluation of automated SEM/EDS data can be performed.

To identify active inclusions in the SEM, the AF microstructure needs to be at least slightly visible in the SEM image. Thus, inclusion characterization was performed in two steps: The overall inclusion population in each sample was analyzed on a metallographic specimen of the cast sample (see slice 1 in Figure 1) with automated SEM/EDS analyses directly after the melting experiment in the Tammann-type Furnace. After heat treatment of slice 2 samples in the LSCM, each sample was again prepared metallographically and additionally etched with Nital for microstructural characterization in the optical microscope. These etched samples were also manually analyzed in the SEM to determine the active inclusion types. For each sample, 150 inclusions were manually characterized.

\section{E. Material Tests}

As a last step, tensile tests were performed on selected heat-treated samples using a method enabling testing circular tensile specimens with thicknesses in the micron or even sub-micron regime. Sample preparation and testing was done applying the method developed by Rathmayr et al. ${ }^{[32]}$ To avoid additional damage of the specimen, the whole preparation procedure was performed using a specifically developed grinding tool combined with an appropriate clamping and continuous liquid cooling. The applied standard geometry of the test specimens with a test length of $2.5 \mathrm{~mm}$ and a nominal diameter of $500 \mu \mathrm{m}$ is illustrated in Figure 3. During testing, the maximum weight of standard specimens was about $250 \mathrm{~N}$. Thus, a $2-\mathrm{kN}$ load cell was used. The error was estimated according to Eq. [1],

$$
\Delta \sigma=\sqrt{\left(\frac{4}{\pi d^{2}} \Delta F\right)^{2}+\left(\frac{-8 F}{\pi d^{3}} \Delta d\right)^{2}}
$$

where $d$ is the sample diameter and $\mathrm{F}$ is the maximum drag force. Further details regarding preparation of specimens as well as the test procedure are given in Reference 32. Due to the comparable large effort of sample preparation and testing, only a limited number of samples have been tested. With samples C1-1 and C2-1, two conditions very different from each other regarding the acicular ferrite amount but comparable carbon content as well as heat-treatment conditions have been selected. For each condition, three samples were heat treated, and the analyzed samples were investigated. The tested samples were subsequently analyzed in the SEM for measuring the diameter reduction through the induced tensile stress (= remaining fracture area). The ductility $Z$ thus realized is calculated according to Eq. [2]:

$$
Z=\left(\frac{A_{0}-A_{1}}{A_{0}}\right) \times 100,
$$


where $A_{0}$ is the initial cross-sectional area and $A_{1}$ is the remaining fracture area.

\section{RESULTS}

\section{A. Acicular Ferrite Amount}

As described in Section II, microstructures have been analyzed for all samples after heat treatment in the HT-LSCM. The results are displayed in Figure 4. For each sample, a mean value obtained by analyzing three different positions on the sample is given. In all cases, the microstructure is very homogeneous over the whole sample area. By means of HT-LSCM, the formation of acicular ferrite was observable in situ, as shown for sample A1-1 in Figure 5. It is clearly observed that a needle nucleated on an active nonmetallic inclusion. The needle grew with the ongoing cooling process until the impingement with another transformation product.

Steels A3 and A1 provided the highest potential for acicular ferrite, showing a percentage of greater than 70 pct in the final microstructure (see Figures 6 and 7). Also in steel C1, a significant potential for acicular ferrite was observed. Samples A2 and B1 show only limited potential for acicular ferrite formation under the defined conditions. In the case of A2 also, variations in the heat-treatment and cooling parameters do not improve the results (see Figure 6). One of the major reasons for the low AF content in A2 is the very low matrix content of manganese. Details regarding this aspect will be given in a later subsection.

In the current study, steels without titanium were inactive for acicular ferrite. For example, in steel C1 with 0.03 wt pct titanium, an acicular ferrite fraction of 44 pct resp. 59 pct depending on the cooling rate was detected. Without titanium addition, no acicular ferrite formed regardless of the cooling rate, due to a lack of Ti-rich inclusions that act as active nucleation sites (see Figure 8).

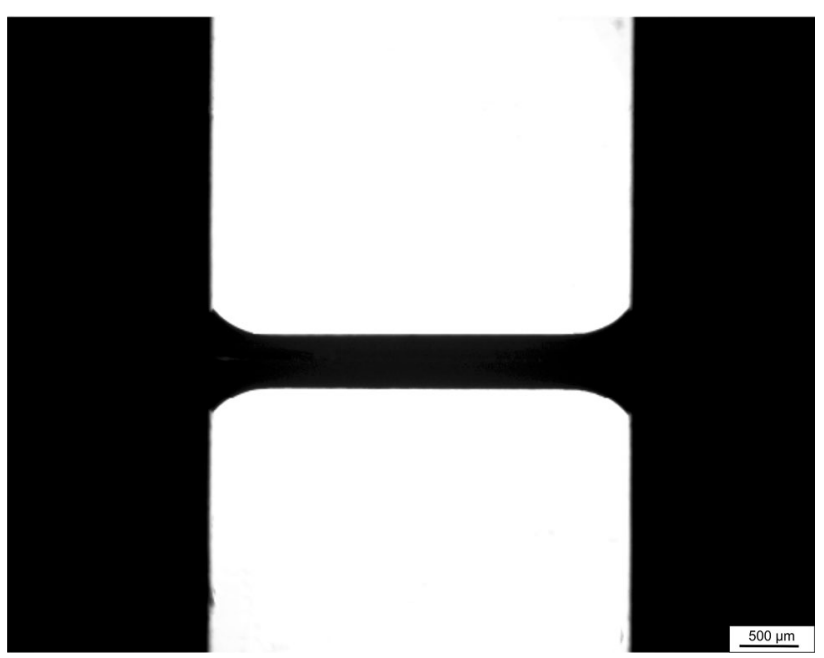

Fig. 3-Transmitted light image of a test specimen with standard geometry.
Steel B1 exhibited a lower potential for forming acicular ferrite than steels $\mathrm{A}$ and $\mathrm{C}$ did; nevertheless, still 8 pct acicular ferrite grains are found. Figure 9 clearly displays that acicular ferrite grains formed in steel B were significantly shorter than the grains formed in steels A or C.

Steel D provided no potential for forming acicular ferrite due to the steel's composition. The high carbon content of the pearlitic steel suppressed the formation of acicular ferrite completely; consequently, the capability of inclusions in steel D to act as nuclei for acicular ferrite could not be studied.

\section{B. Active Inclusion Types in Steels $A, B$, and $C$}

Figure 10(a) summarizes the results of manual and automated SEM/EDS analyses for representative examples of steels A, B, and C. For each case, all detected inclusion types are displayed with their percentages (in black) in relation to the absolute number of detected inclusions. In addition, their percentages (in red) also within the total number of active inclusions are given. The ratio between these two values helps to evaluate inclusions' acicular ferrite nucleation potential; the higher the ratio of active percentage to total percentage, the higher the inclusion type's potential.

Considering the absolute number of detected inclusions, a variation between 200 and 300 inclusions per $\mathrm{mm}^{2}$ between the analyzed samples is found. This deviation is seen as quite homogeneous and comparable since samples have not been deformed before SEM/EDS analyses. Nevertheless, sample A1-1 shows the highest number of detected inclusions per $\mathrm{mm}^{2}$, followed by sample A2-1. Inclusion numbers in samples B1 and C1-1 are very similar around 200 per $\mathrm{mm}^{2}$. The lower inclusion number in these samples would correspond to a lower content of AF compared with A1-1, for example. However, the inclusion number in A2-1 is close to A1-1, but the AF content is much lower. Of course, an adequate minimum number of possible nucleation

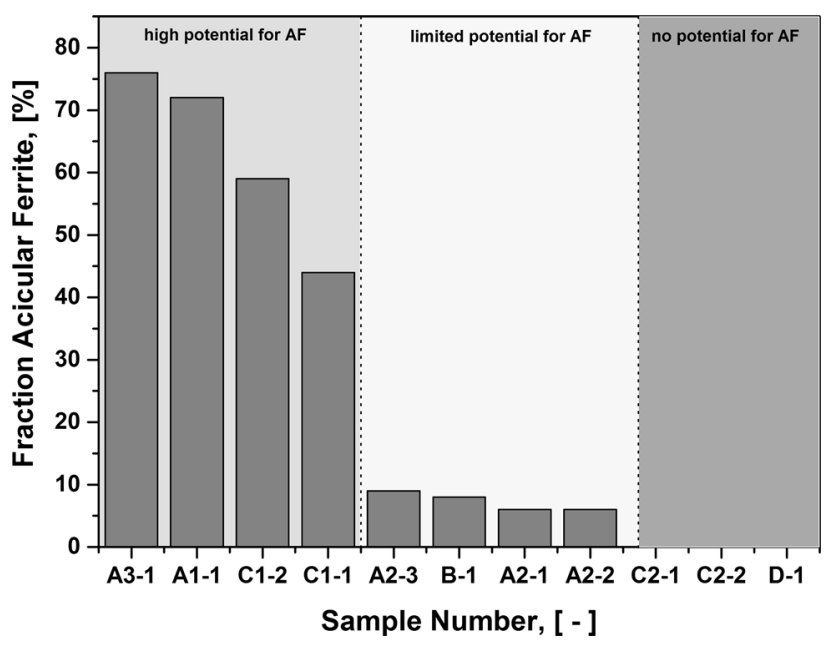

Fig. 4 - Comparison of acicular ferrite fraction in the analyzed samples. 


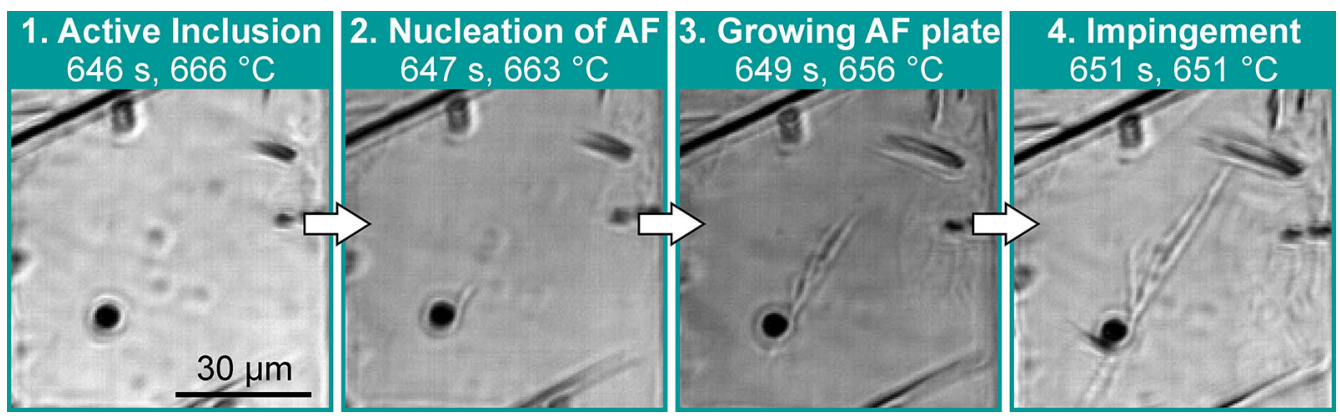

Fig. 5-In situ observation of acicular ferrite plates nucleating on inclusion and growing until impingement in steel A1-1 during HT-LSCM treatment.
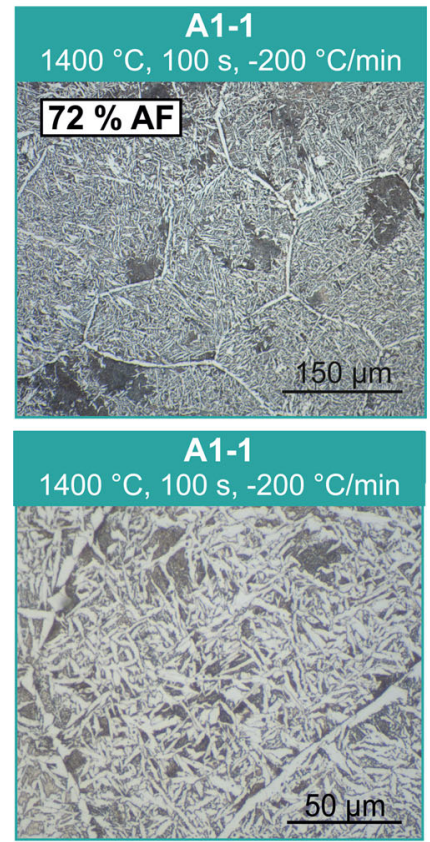
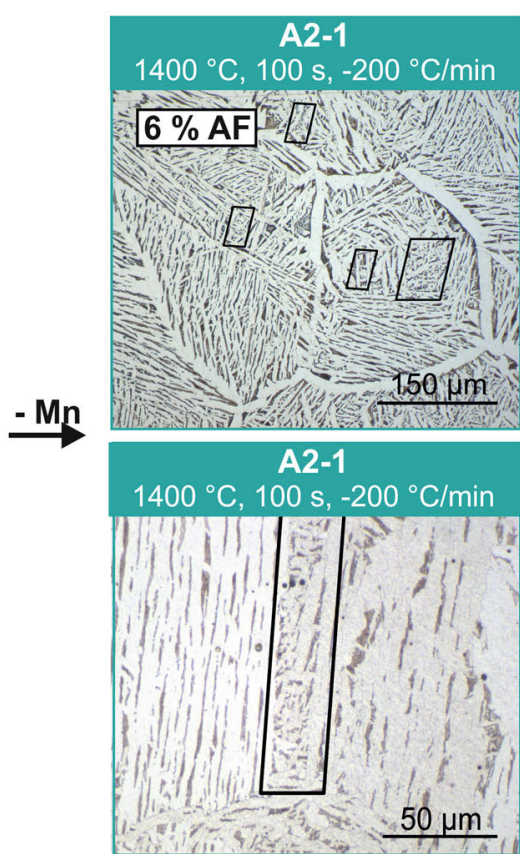

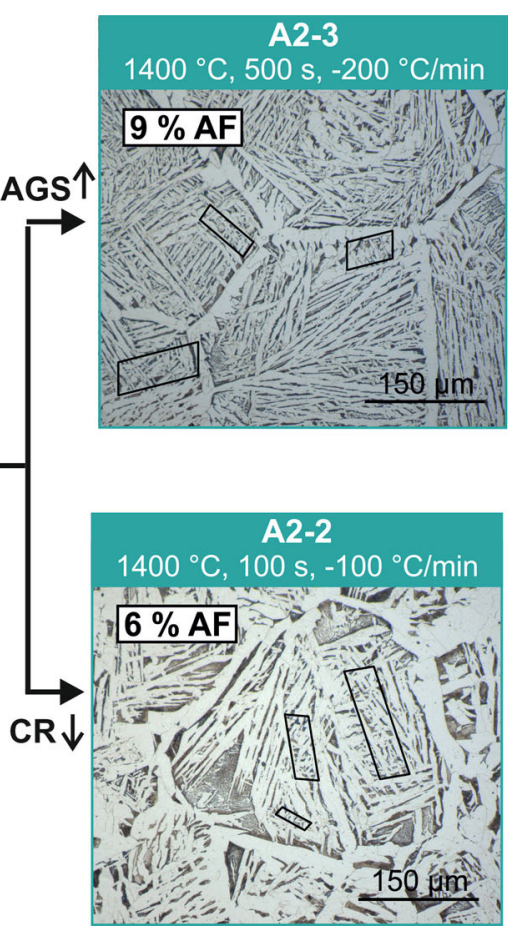

Fig. 6-Decrease of acicular ferrite amount in steel grade A without manganese addition, for varying austenite grain sizes and cooling rates.

sites is necessary. However, the absolute inclusion number can be very high - if there are not enough active inclusions present, AF formation is not promoted.

Figure 10(b) summarizes the detected inclusion size ranges for every inclusion type in a representative sample for each steel grade. The mean Equivalent Circle Diameter (ECD) of most inclusions (marked with the small square in each box) is below $2 \mu \mathrm{m}$, and except $\mathrm{Al}_{2} \mathrm{O}_{3}$ inclusions in B-1 for every type, 75 pct of all the detected inclusions are smaller than $2.5 \mu \mathrm{m}$ ECD (defined through the upper line of each box). The upper size limit for 99 pct of inclusions is marked with a cross for each case. In the literature, several authors ${ }^{[33-36]}$ described a boost in nucleation potential with the increasing inclusion size, which is in good accordance with earlier findings of Ricks et al. ${ }^{[37,38]}$ However, it should be noted that in many cases also, a lower and an upper critical sizes for active inclusions are defined. The lower critical value is the minimum size beneath which particles are too small to act as active nuclei. This value was determined to be 0.3 to $0.5 \mu \mathrm{m}$ in various studies. ${ }^{[34,39,40]}$ Ricks et al..$^{[37,38]}$ Lee et al. ${ }^{[34]}$ and $\mathrm{Mu}$ et al. ${ }^{[33-36]}$ investigated inclusions smaller than $1.5 \mu \mathrm{m}$ and defined $1 \mu \mathrm{m}$ as the upper critical value. Above $1 \mu \mathrm{m}$, the probability curve flattens out. Huang et al. ${ }^{[34,39,40]}$ who considered inclusions up to $7 \mu \mathrm{m}$, observed $1.5 \mu \mathrm{m}$ as the upper critical value but described a sharp decrease in the nucleation probability above $4 \mu \mathrm{m}$, resulting in inert behavior of inclusions larger than $6.5 \mu \mathrm{m}$. Similar results were gained by Song et al. ${ }^{[41]}$ and Wang et al. ${ }^{[42]}$ who found inclusions with sizes ranging from 1 to $3 \mu \mathrm{m}$ and 1 to $2 \mu \mathrm{m}$, respectively, as the most appropriate nuclei. Inclusions below and 


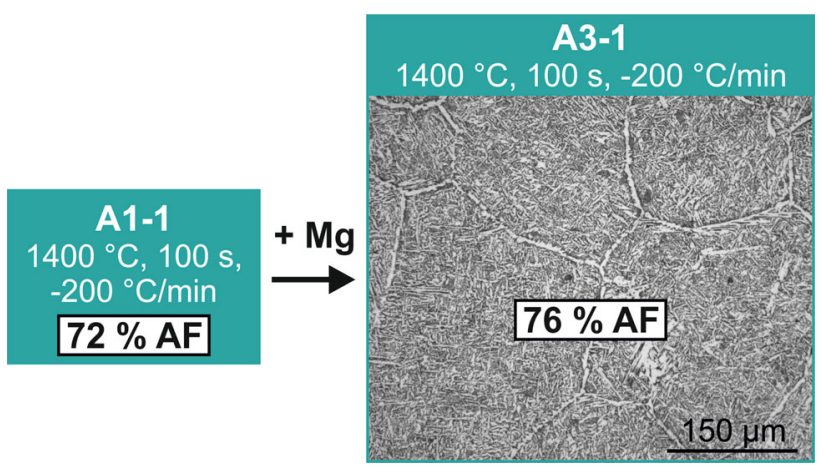

Fig. 7-Influence of magnesium on the fraction of acicular ferrite in steel A.

above these ranges were less active. The inclusion sizes observed in the present study were all in a very similar range and in good agreement to the values defined as appropriate in the literature. For these reasons, the influence of inclusion size was not further studied in this study. Instead, the current study was focused on inclusion composition and inclusion morphology. In the following, detailed results for samples A1-1, B-1, and $\mathrm{C} 1-1$ are discussed.

\section{Steel A1}

- Pure titanium oxides or titanium oxides with small amounts of dissolved manganese were detected in the sample. Pure $\mathrm{TiO}_{\mathrm{x}}$ was not found as acicular ferrite nuclei in this steel. $(\mathrm{Ti}, \mathrm{Mn}) \mathrm{O}_{\mathrm{x}}$ was identified as highly active in steel $\mathrm{Al}$; despite $(\mathrm{Ti}, \mathrm{Mn}) \mathrm{O}_{\mathrm{x}}$ representing only a small fraction of the total inclusion number, 10 pct of the active inclusions were of this type.

- $\mathrm{TiO}_{\mathrm{x}}$ was very often found in combination with $\mathrm{MnS}$ forming $(\mathrm{Ti}, \mathrm{Mn}) \mathrm{O}_{\mathrm{x}} \mathrm{S}_{\mathrm{y}}$ particles. This inclusion type was found to be composed of a $\mathrm{TiO}_{\mathrm{x}}$-containing core and a $\mathrm{MnS}$ layer. Due to the interacting volume during EDS analysis and the resulting overlap of signals from $\mathrm{TiO}_{\mathrm{x}}$ and $\mathrm{MnS}$, no definitive statement about dissolved manganese in the $\mathrm{TiO}_{\mathrm{x}}$ could be made. (Ti, Mn) $\mathrm{O}_{\mathrm{x}} \mathrm{S}_{\mathrm{y}}$ had proven to be an effective nucleation site for acicular ferrite; 7 pct of the active inclusions in steel A1 were of this composition.

- Due to the reaction with the used alumina crucible, $\mathrm{Al}_{2} \mathrm{O}_{3}$ was frequently included in the nonmetallic inclusions. High amounts of $(\mathrm{Ti}, \mathrm{Al}) \mathrm{O}_{\mathrm{x}}$ and $(\mathrm{Ti}, \mathrm{Mn}, \mathrm{Al}) \mathrm{O}_{\mathrm{x}}$ inclusions were found in the sample A1. Manual SEM/EDS analyses revealed these inclusions were composed of homogeneous oxidic phases or multiphase inclusions consisting of $\mathrm{Al}_{2} \mathrm{O}_{3}$, $\mathrm{TiO}_{\mathrm{x}}$, and $(\mathrm{Ti}, \mathrm{Mn}) \mathrm{O}_{\mathrm{x}}$. The manual analyses of active inclusions revealed that $(\mathrm{Ti}, \mathrm{Al}) \mathrm{O}_{\mathrm{x}}$ particles accounted for $10 \mathrm{pct}$ of the acicular ferrite nuclei. $(\mathrm{Ti}, \mathrm{Mn}, \mathrm{Al}) \mathrm{O}_{\mathrm{x}}$ was also confirmed as an active type, but with a low potential. Although $(\mathrm{Ti}, \mathrm{Mn}, \mathrm{Al}) \mathrm{O}_{\mathrm{x}}$ was the most common inclusion type in steel A1, only 14 pct of the acicular ferrite nuclei were of this type.

- Occasionally, $(\mathrm{Ti}, \mathrm{Al}) \mathrm{O}_{\mathrm{x}}$ and $(\mathrm{Ti}, \mathrm{Mn}, \mathrm{Al}) \mathrm{O}_{\mathrm{x}}$ inclusions had a MnS layer. The formed (Ti,Mn, Al) $\mathrm{O}_{\mathrm{x}} \mathrm{S}_{\mathrm{y}}$ inclu- sions were highly active and represented 38 pct of the active particles in this grade.

- MnS was found to nucleate heterogeneously on preexisting oxidic phases in many cases, but a significant amount of pure $\mathrm{MnS}$ particles were also detected. $\mathrm{MnS}$ was asserted to be an effective inclusion type because 7 pct of the analyzed acicular ferrite nuclei were of pure $\mathrm{MnS}$.

- In addition, TiN was found, which was determined to be inert for acicular ferrite nucleation in steel A1.

\section{Steel B1}

- $(\mathrm{Ti}, \mathrm{Mn}, \mathrm{Al}) \mathrm{O}_{\mathrm{x}}$ inclusions were identified in sample $\mathrm{B} 1$ by automated SEM/EDS. As previously explained, based on the automated SEM/EDS results, this type of inclusions could not be distinguished between homogenous and multiphase $\mathrm{TiO}_{\mathrm{x}}-(\mathrm{Mn}) \mathrm{Al}_{2} \mathrm{O}_{3}$ particles. However, this inclusion type was not found as nuclei for acicular ferrite in steel B; however, it was active in steel A1.

- MnS was detected as a stable inclusion phase in steel B. Despite the small number, MnS represented 25 pct of the active inclusions in steel B. Like in steel $\mathrm{A} 1,(\mathrm{Ti}, \mathrm{Mn}) \mathrm{O}_{\mathrm{x}} \mathrm{S}_{\mathrm{y}}$ inclusions were formed by heterogeneous nucleation, but in contrast to steel A1, this type was ineffective in steel B.

- The largest fraction of all inclusions and, also, the largest fraction of active inclusions (75 pct) was that of $(\mathrm{Ti}, \mathrm{Mn}, \mathrm{Al}) \mathrm{O}_{\mathrm{x}} \mathrm{S}_{\mathrm{y}}$. Therefore, this inclusion type was identified as highly active.

- As in steel A1, high alumina inclusions were found in steel B1 owing to the crucible material. These inclusions were found to be inert in the present case, in accordance with most reports in the literature. $^{[5,9,19,40,43-45]}$

\section{Steel C1}

- Considerable amounts of ( $\mathrm{Ti}, \mathrm{Mn}, \mathrm{Al}, \mathrm{Si}) \mathrm{O}_{\mathrm{x}}$ particles were detected in steel $\mathrm{Cl}$. However, this inclusion type was identified as inactive for acicular ferrite, contrasting with the literature reports. ${ }^{[12,13,42]}$

- Small amounts of pure MnS particles were found in steel C1. Most MnS particles were composed of a heterogeneously nucleated layer on oxidic inclusions. Nevertheless, $15 \mathrm{pct}$ of the active inclusions in steel $\mathrm{C} 1$ were pure $\mathrm{MnS}$. Hence, $\mathrm{MnS}$ was confirmed as highly active in steel $\mathrm{Cl}$.

- No pure $\mathrm{TiO}_{\mathrm{x}}$ was contained in this steel. However, small amounts of $(\mathrm{Ti}, \mathrm{Mn}) \mathrm{O}_{\mathrm{x}} \mathrm{S}_{\mathrm{y}}$ inclusions were encountered, which consisted of a titanium-containing oxidic core and a MnS layer. As explained before, it was not possible to distinguish between $\mathrm{TiO}_{\mathrm{x}}$ and $(\mathrm{Ti}, \mathrm{Mn}) \mathrm{O}_{\mathrm{x}}$ cores. $10 \mathrm{pct}$ of the active inclusions in steel $\mathrm{C} 1$ were of the $(\mathrm{Ti}, \mathrm{Mn}) \mathrm{O}_{\mathrm{x}} \mathrm{S}_{\mathrm{y}}$ type.

- The mixed oxides in this steel, containing titanium, manganese, aluminum, and/or silicon, often showed layers of $\mathrm{MnS}$, forming complex oxysulfides. Although the literature suggests $(\mathrm{Ti}, \mathrm{Mn}, \mathrm{Si}) \mathrm{O}_{\mathrm{x}} \mathrm{S}_{\mathrm{y}}$ as active, this inclusion type did not promote the 

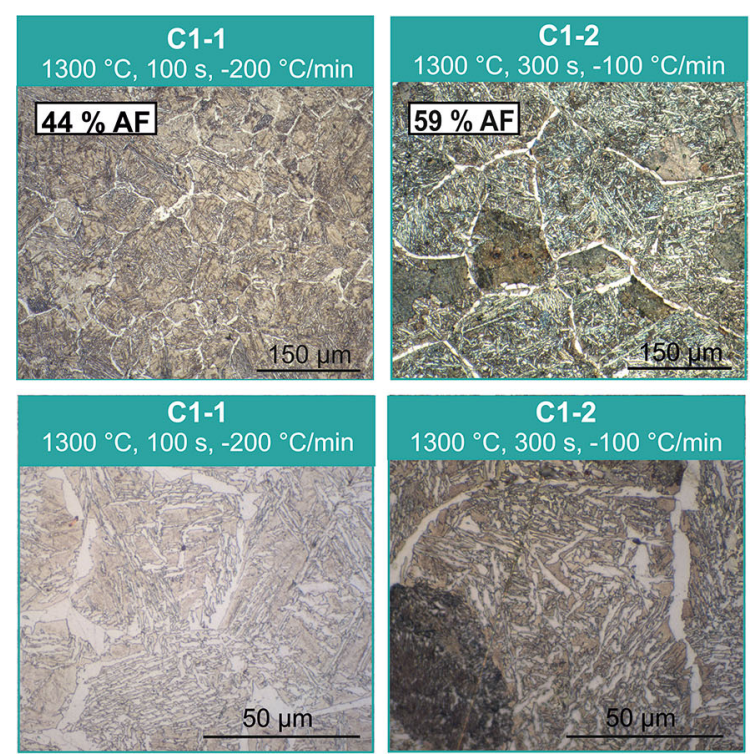
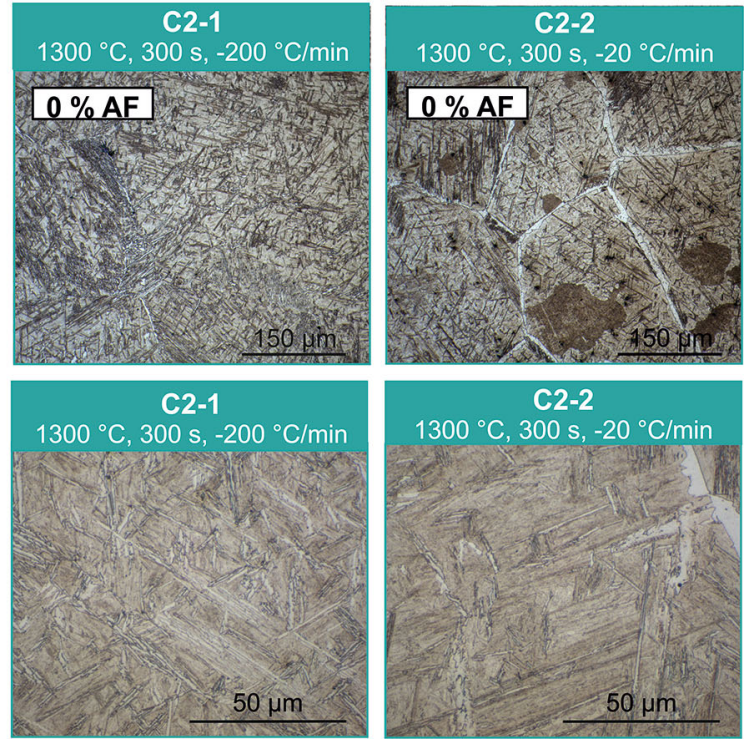

Fig. 8- Suppression of acicular ferrite formation in steel C without titanium, for varying cooling rates.

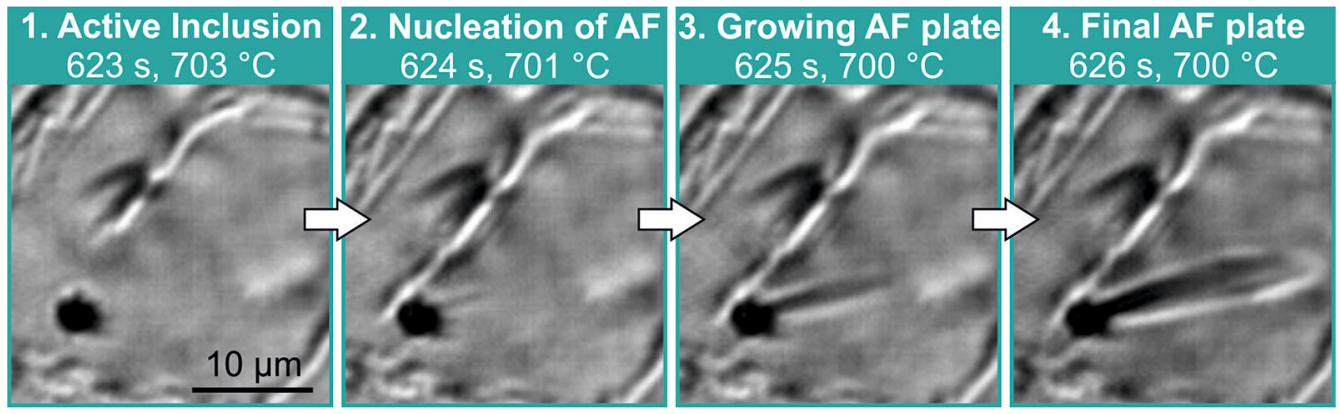

Fig. 9-Nucleation and growth of an acicular ferrite needle in steel B-1 during HT-LSCM treatment.

nucleation of acicular ferrite in steel $\mathrm{C} 1$. In accordance with other reports, (Ti, Mn, $\mathrm{Al}, \mathrm{Si}) \mathrm{O}_{\mathrm{x}} \mathrm{S}_{\mathrm{y}}$ was found as an operative nuclei type, albeit only occasionally. $(\mathrm{Mn}, \mathrm{Si}) \mathrm{O}_{\mathrm{x}} \mathrm{S}_{\mathrm{y}}$ has been described as inert in the literature, but it was sporadically found as nuclei in this study. These differences between the present observations and the literature may be the result of the variations in the steel compositions.

- The SEM/EDS identified a considerable amount of TiN-containing inclusions. There were no, or at least inconsistent, descriptions of these inclusion classes found in the literature. The current results demonstrate that $(\mathrm{Ti}, \mathrm{Mn}, \mathrm{Si}) \mathrm{O}_{\mathrm{x}} \mathrm{S}_{\mathrm{y}} \mathrm{N}$ inclusions were inactive.

- $(\mathrm{Ti}, \mathrm{Al}) \mathrm{O}_{\mathrm{x}},(\mathrm{Ti}, \mathrm{Mn}, \mathrm{Al}) \mathrm{O}_{\mathrm{x}}$, and $(\mathrm{Ti}, \mathrm{Mn}, \mathrm{Al}) \mathrm{O}_{\mathrm{x}} \mathrm{S}_{\mathrm{y}}$ inclusions accounted for only a very small fraction of the total inclusions in steel $\mathrm{Cl}$, but these types have been demonstrated to be highly active for acicular ferrite nucleation, as they represent 10,15 , and 20 pct, respectively, of the acicular ferrite nuclei in this steel.

\section{Interaction of Solute Manganese and Manganese Inclusions}

Manganese is commonly described as crucial for the formation of acicular ferrite in the literature. ${ }^{[8,46-48]} \mathrm{In}$ general, the migration of manganese in nonmetallic inclusions and the resulting manganese-depleted zones has been observed as the trigger mechanism for acicular ferrite nucleation. To investigate the effect of manganese fluctuations in the matrix on the acicular ferrite formation, steel A1 was compared with steel A2, which is identical in chemical composition, except that no additional manganese was added to steel A2 in the Tammann-type Furnace experiment. However, as shown in Figure 11, huge amounts of manganese-containing inclusions were detected in the sample. This is explained by the fact that the raw material also already contains $0.07 \mathrm{wt}$ pct $\mathrm{Mn}$ as well as a preexisting inclusion population. Automated SEM/EDS analyses of the raw material showed $\mathrm{Al}_{2} \mathrm{O}_{3},(\mathrm{Al}, \mathrm{Mn}) \mathrm{O}_{\mathrm{x}},(\mathrm{Si}, \mathrm{Mn}) \mathrm{O}_{\mathrm{x}}, \mathrm{MnS}$ and $(\mathrm{Al}, \mathrm{Mn}) \mathrm{O}_{\mathrm{x}} \mathrm{S}_{\mathrm{y}}$ as the predominant inclusion types. 

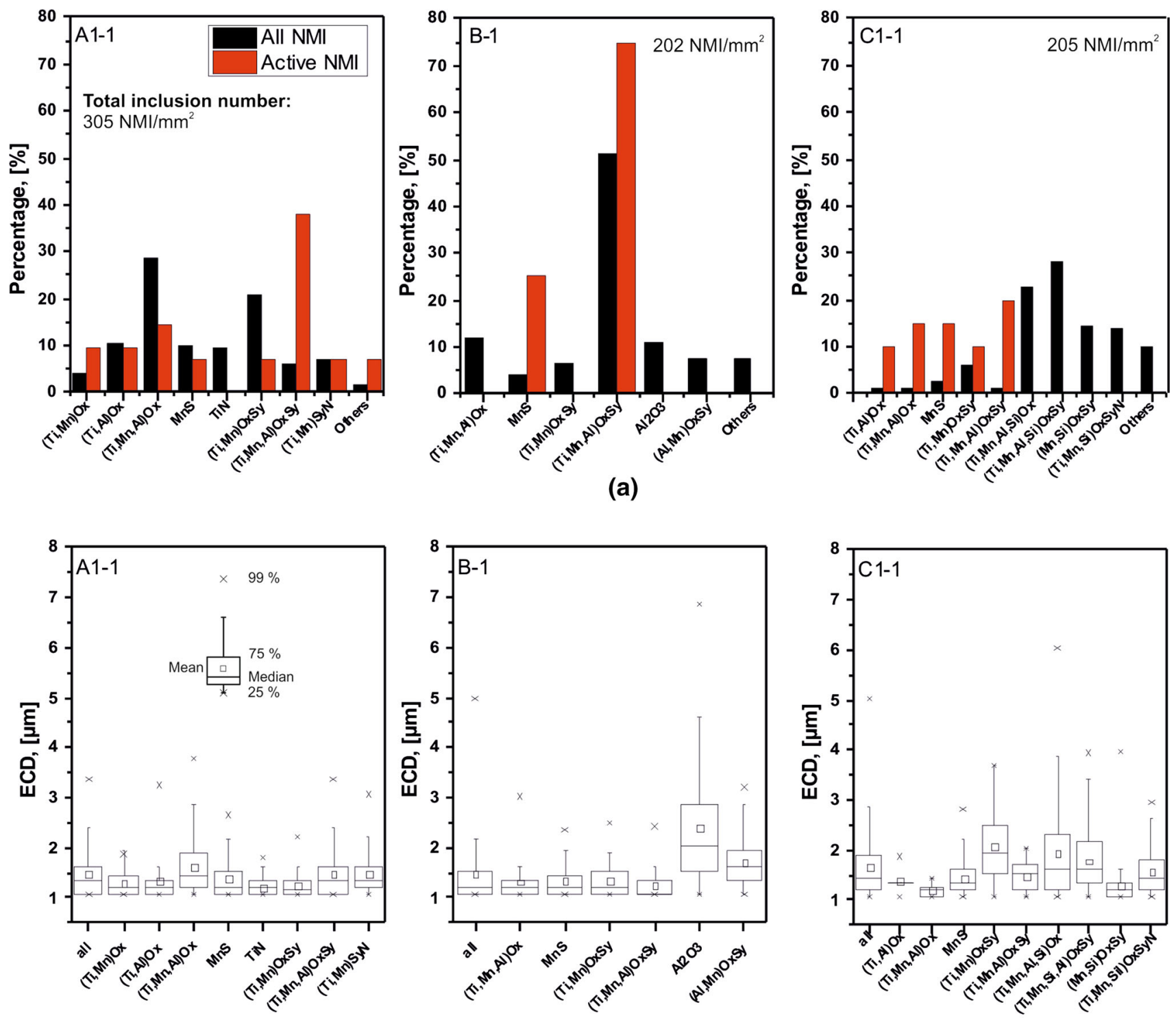

(b)

Fig. 10 - (a) Percentages of active inclusion types in relation to the total percentages of various inclusion types and $(b)$ Mean size ranges of main inclusion types in steels $\mathrm{A}, \mathrm{B}$, and $\mathrm{C}$.

Although the overall inclusion population in the raw material is low compared with the inclusion content after the melting experiment, these preexisting inclusions can influence the final inclusion landscape, for example, through modification to $(\mathrm{Ti}, \mathrm{Mn}, \mathrm{Al}) \mathrm{O}_{\mathrm{x}}$. The formation of new high Mn-containing inclusions in this sample only plays a minor role. Furthermore, it has to be mentioned that the percentage of $\mathrm{Mn}$ in these complex $(\mathrm{Ti}, \mathrm{Mn}, \mathrm{Al}) \mathrm{O}_{\mathrm{x}}$ inclusions is very low. Inclusion sizes are comparable to A1-1 except the type $(\mathrm{Ti}, \mathrm{Al}) \mathrm{O}_{\mathrm{x}}$ which shows several outliers above $5 \mu \mathrm{m}$ ECD. However, as already shown in Figure 6, only a low acicular ferrite amount was produced without additional manganese addition in steel A2. With the significantly lower manganese content, the microstructure changed from highly acicular ferritic one to mainly Widmannstätten ferritic type with pearlite and considerable amounts of grain boundary ferrite. A decrease in the cooling rate (CR) increased the amount of pearlite and grain boundary ferrite, but not that of acicular ferrite. Widmannstätten ferrite is a grain boundary nucleated phase; nevertheless, a reduction of the grain boundary surface by increasing the austenite grain size (AGS) also did not enhance the intragranular nucleation.

The characterization of the inclusion landscape demonstrated that the suppression of acicular ferrite in steel A2 was not the result of the absence of manganese-containing inclusions, but the result of lacking soluble manganese. Sample A2 contains inclusion types that were already identified as active in steel A1. Although detailed phase characterization as well as a differentiation between homogeneous and heterogeneous inclusions for 


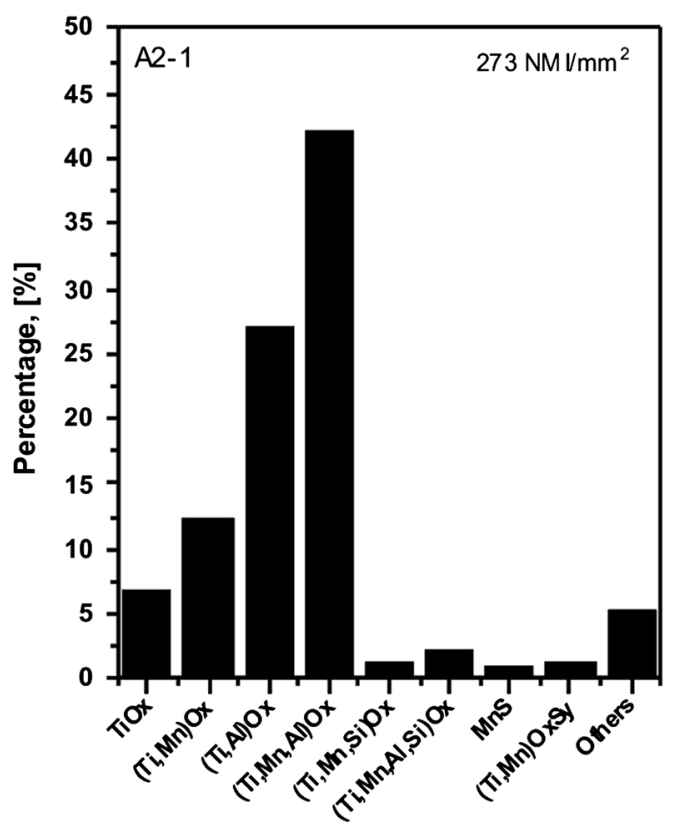

(a)

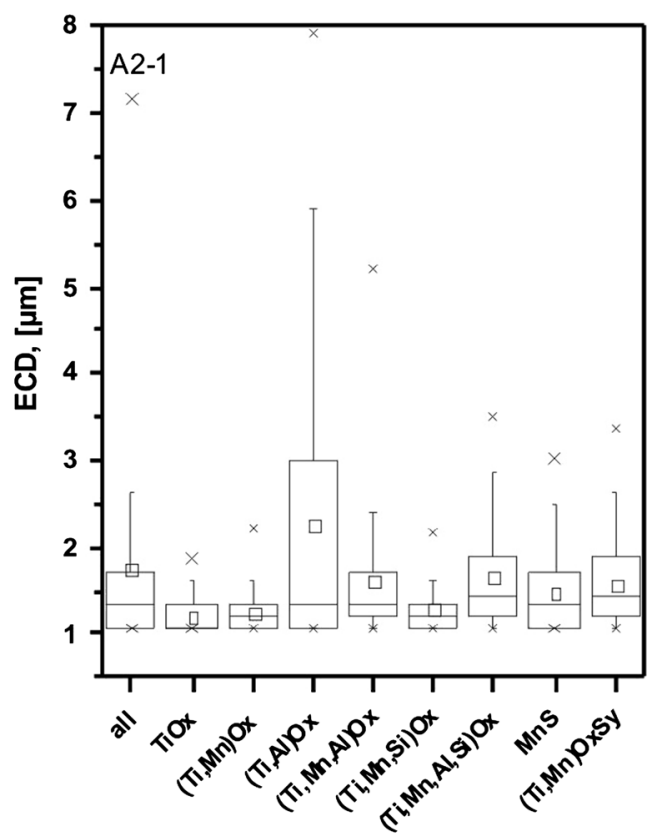

(b)

Fig. 11-(a) Inclusion types and (b) size ranges of inclusions present in steel sample A2-1.
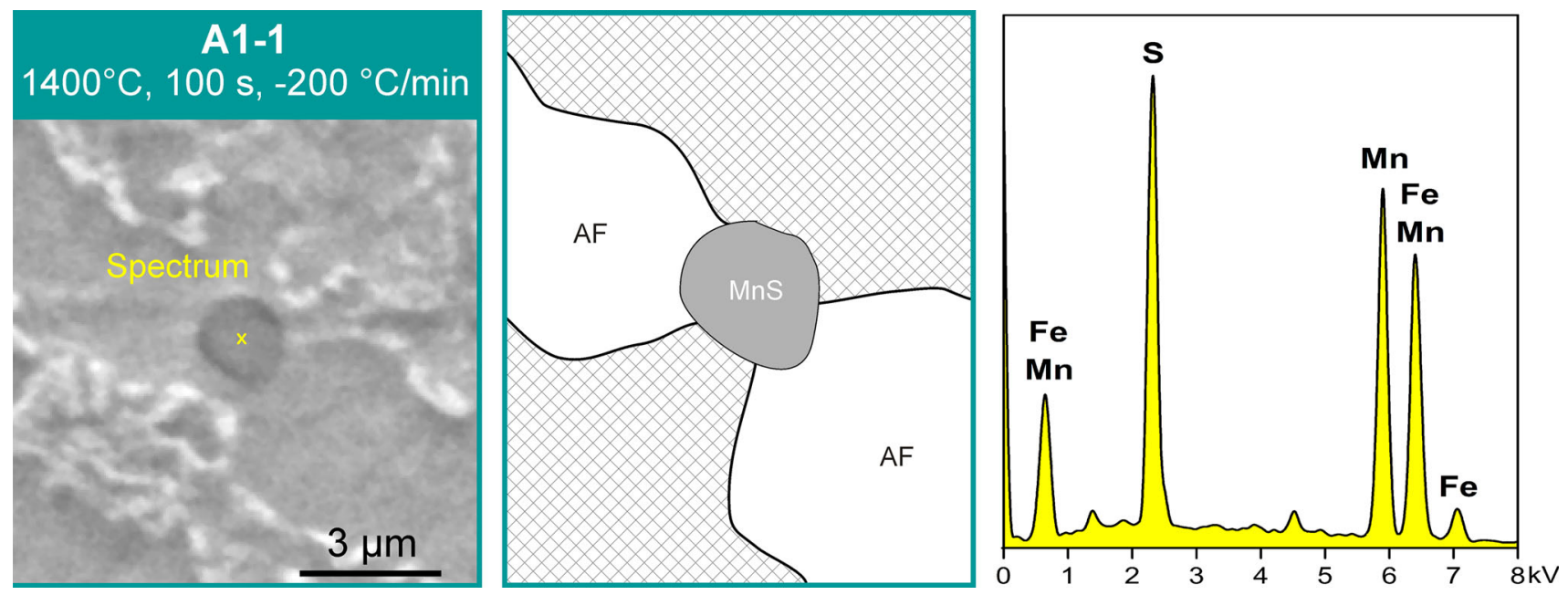

Fig. 12-Active MnS particles in steel A1-1.

sizes $<2 \mu \mathrm{m}$ ECD is difficult with the applied SEM, one interesting difference regarding $(\mathrm{Ti}, \mathrm{Mn}, \mathrm{Al}) \mathrm{O}_{\mathrm{x}}$ as the inclusion type has been observed: The Mn-content in (Ti, Mn, $\mathrm{Al}) \mathrm{O}_{\mathrm{x}}$ inclusions was slightly higher in A1 compared with A2, which could additionally influence the crystal structure and further might contribute to the inclusions' nucleation potential for AF. However, ( $\mathrm{Ti}, \mathrm{Mn}, \mathrm{Al}) \mathrm{O}_{\mathrm{x}}$ inclusions detected in $\mathrm{A} 1$ and $\mathrm{B} 1$ show comparable ratios between $\mathrm{Ti}, \mathrm{Al}$, and $\mathrm{Mn}$ and should therefore feature the same nucleation potential. This inclusion type is active in A1 and inactive in B1. Further investigations applying other methods (e.g.,
WDS) are necessary to investigate this effect in more detail.

These results support the theory about the strong interaction between inclusions and steel composition. Steel A1 contained 1.48 wt pct manganese. The migration of manganese in nonmetallic inclusions led to a local zone with significantly lower manganese content in the matrix. Inclusions that were surrounded by manganese-depleted zones became more favorable for ferrite nucleation than grain boundaries where the manganese content remained unchanged. However, if the manganese content in the matrix was already very low, as in 

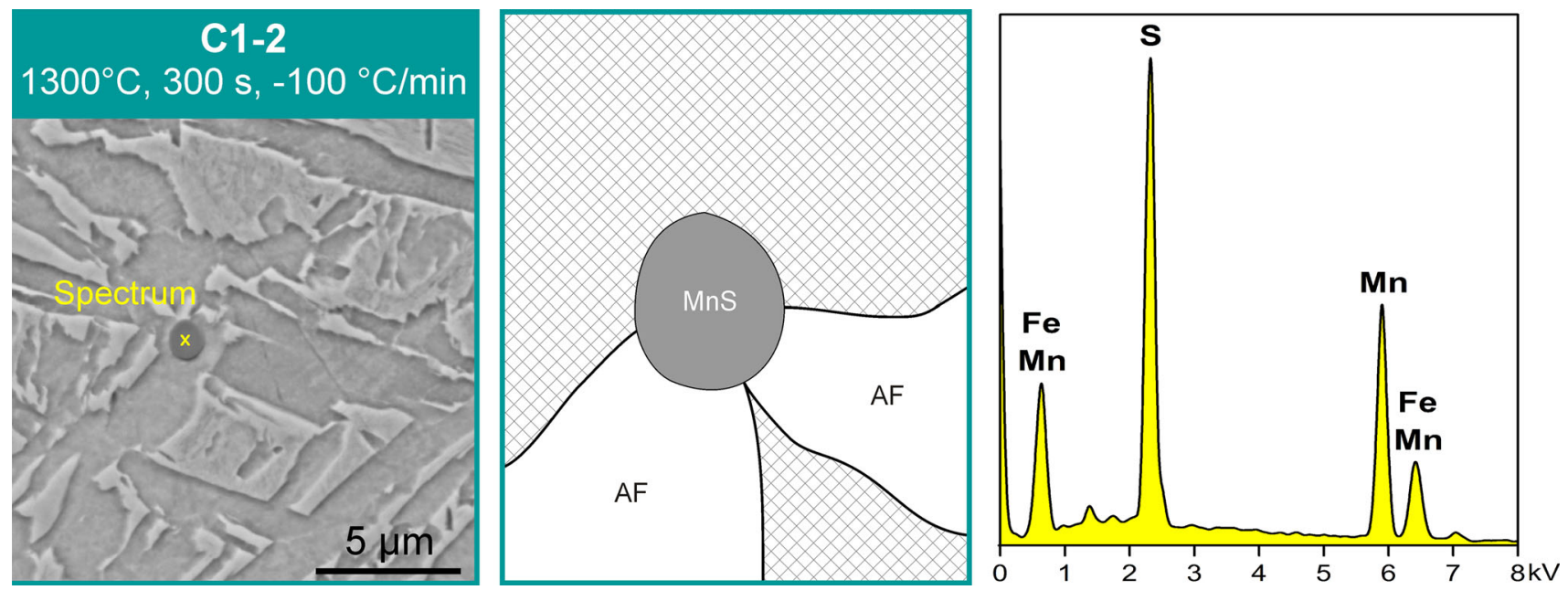

Fig. 13-Active MnS particles in steel C1-2.
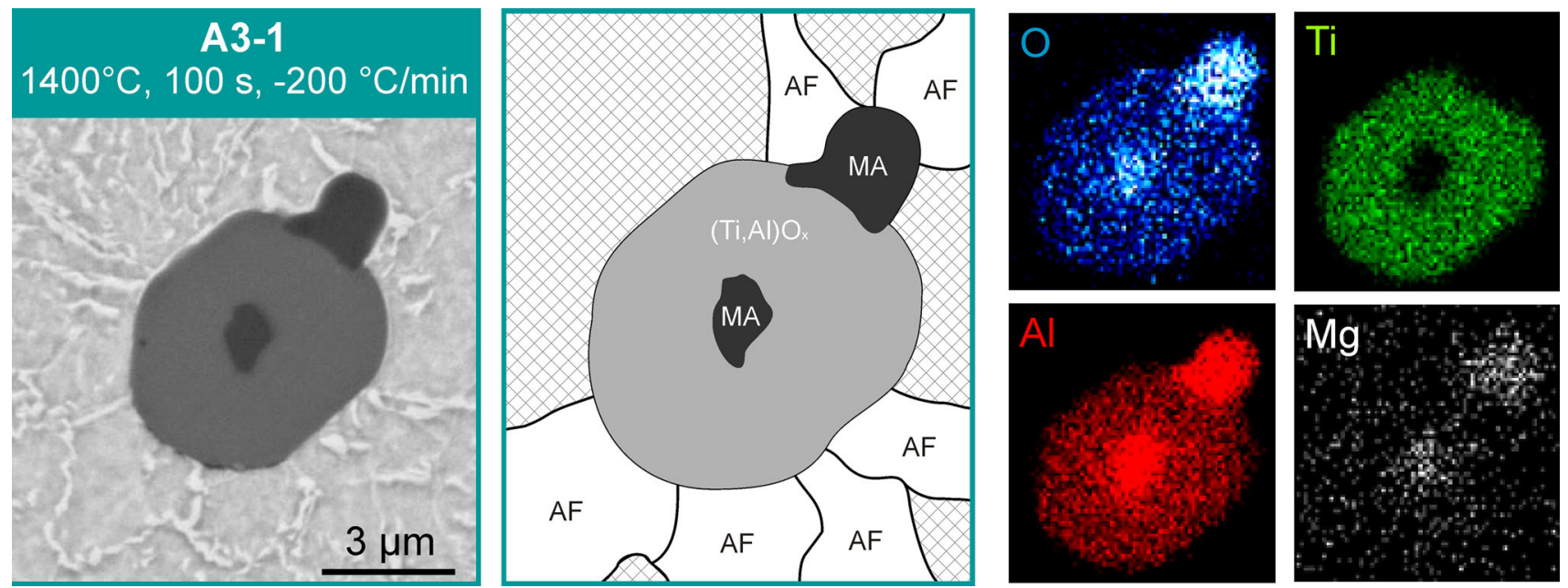

Fig. 14-Active oxidic inclusion in sample A3-1, consisting of a $(\mathrm{Ti}, \mathrm{Al}) \mathrm{O}_{\mathrm{x}}$ particle with a MA-spinel core and an agglomerated MA-spinel particle.
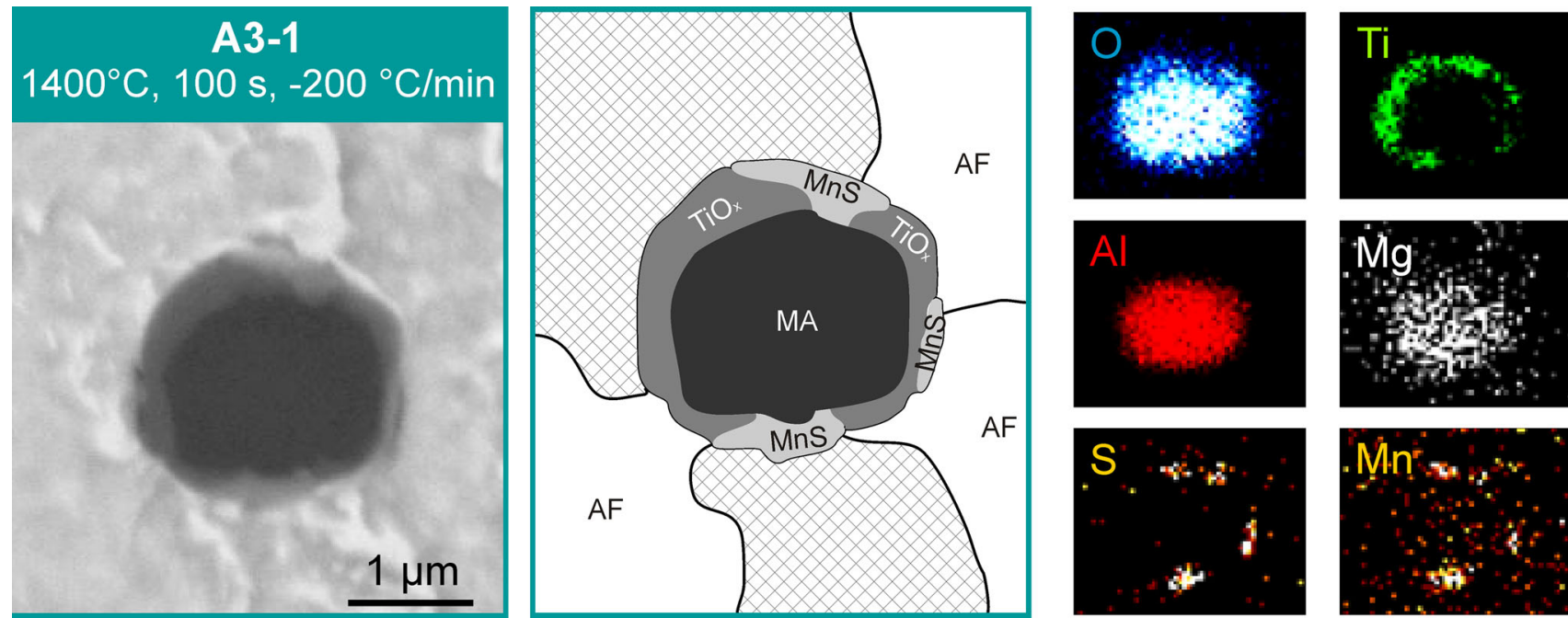

Fig. 15-Active oxysulfidic inclusion in sample A3-1, consisting of a MA-spinel particle with $\mathrm{TiO}_{\mathrm{x}}$ layer and MnS shells. 
steel A2 with $0.07 \mathrm{wt}$ pct, the fluctuations in the manganese content around the inclusions were obviously too small to increase the inclusions' effectiveness to act as nucleation site.

In addition, there are still controversial opinions about the effect of pure $\mathrm{MnS}$ inclusions on acicular ferrite formation. ${ }^{[10,49,50]}$ Pure $\mathrm{MnS}$ particles are often described as inert and only $\mathrm{MnS}$ layers on other inclusion types are observed to promote acicular ferrite formation. In contrast, the results of the current study have shown that pure $\mathrm{MnS}$ particles were also active. In steels A1, B, and C1 single-phase $\mathrm{MnS}$ inclusions were frequently found as nuclei for acicular ferrite (for examples: see Figures 12 and 13).

\section{The Capability of MgO-Modified Inclusions}

$\mathrm{MgO}$-based refractories are widely used in industrial processes, but the effect of magnesium on the formation of acicular ferrite has rarely been investigated. Within the current study, the influence of magnesium in steel A was assessed using $\mathrm{MgO}$ crucibles that react with the steel melt. MgO-based refractory material for steel A3 was used, which led to the formation of $\mathrm{MgOAl}_{2} \mathrm{O}_{3}$ spinel inclusions. For example, Figures 14 and 15 illustrate an oxidic and oxysulfidic, respectively, inclusions with MA-spinel in the core of the particle. Both inclusions acted as nucleation site for several acicular ferrite plates. The inclusion morphology indicated that the reaction with the $\mathrm{MgO}$ crucible and the $\mathrm{Al}_{2} \mathrm{O}_{3}$ stirring equipment led to the formation of MA-inclusions early in the process. Later, these particles operated as heterogeneous nuclei for other inclusion phases like (Ti, Mn,Al) $\mathrm{O}_{\mathrm{x}}$ or $\mathrm{MnS}$ which subsequently act as nuclei for acicular ferrite.

Only a small number of $(\mathrm{Ti}, \mathrm{Al}, \mathrm{Mg}) \mathrm{O}_{\mathrm{x}}$ and (Ti, $\mathrm{Mn}, \mathrm{Al}, \mathrm{Mg}) \mathrm{O}_{\mathrm{x}}$ inclusions were determined by automated SEM/EDS in steel A3; however, the manual
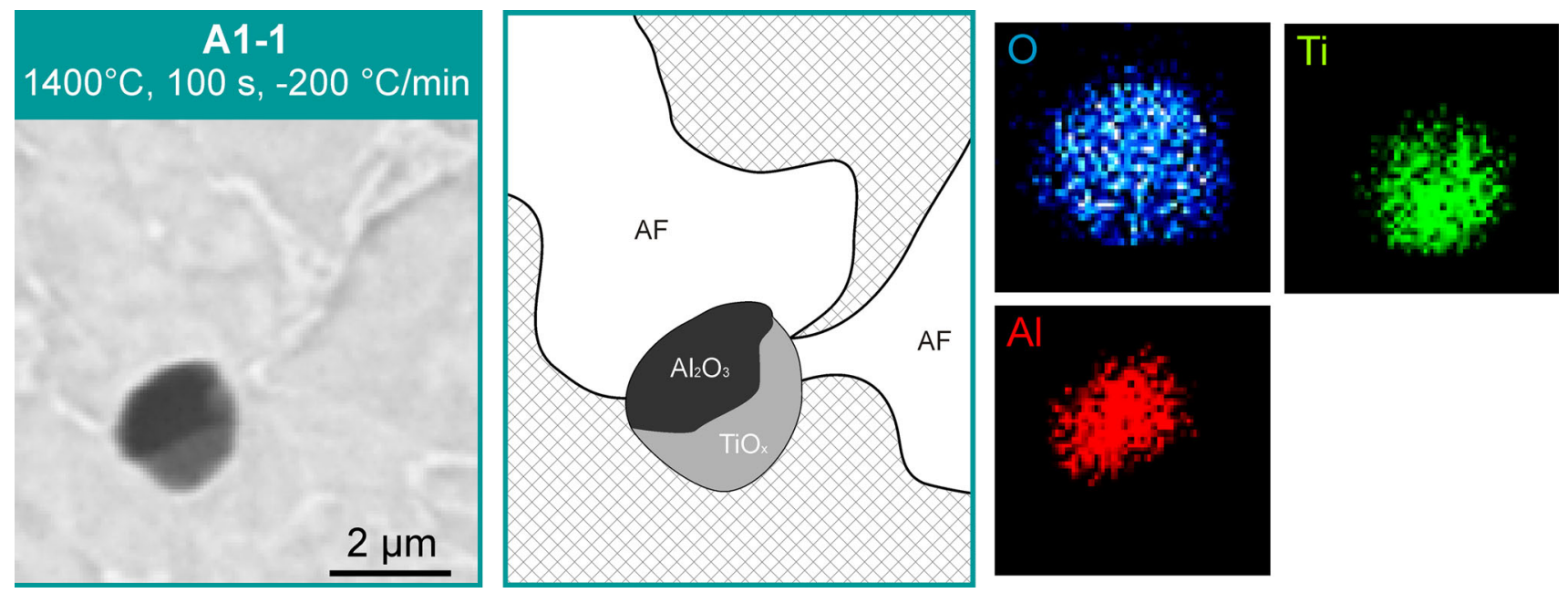

Fig. 16- $(\mathrm{Ti}, \mathrm{Al}) \mathrm{O}_{\mathrm{x}}$ inclusion in sample A1-1, acting as nucleation site for two acicular ferrite plates.

Table IV. Potential of Selected Inclusion Types to Act as Nuclei for Acicular Ferrite in Different Steel Grades

\begin{tabular}{lcccc}
\hline & & Literature & Steel A1 & Steel B \\
\hline $\mathrm{TiO}_{\mathrm{x}}$ & $\sim$ & $5,9,11,12,19,23,43,44,50,51$ & - & \\
$(\mathrm{Ti}, \mathrm{Mn}) \mathrm{O}_{\mathrm{x}}$ & + & $11,14,19,44,50,52$ & + & - \\
$(\mathrm{Ti}, \mathrm{Al}) \mathrm{O}_{\mathrm{x}}$ & $\sim$ & $40,42,51$ & + & + \\
$(\mathrm{Ti}, \mathrm{Mn}, \mathrm{Al}) \mathrm{O}_{\mathrm{x}}$ & + & $11,40,51$ & & - \\
$(\mathrm{Ti}, \mathrm{Mn}, \mathrm{Al}, \mathrm{Si}) \mathrm{O}_{\mathrm{x}}$ & + & $12,13,42$ & + & + \\
$\mathrm{MnS}$ & $\sim$ & $5,9-12,19,21,40,45,50$ & + \\
$(\mathrm{Ti}, \mathrm{Mn}) \mathrm{O}_{\mathrm{x}} \mathrm{S}_{\mathrm{y}}$ & + & $9,11,12,17,20,21,40,42,45$ & + \\
$(\mathrm{Ti}, \mathrm{Mn}, \mathrm{Al}) \mathrm{O}_{\mathrm{x}} \mathrm{S}_{\mathrm{y}}$ & + & 1153 & + & + \\
$(\mathrm{Ti}, \mathrm{Mn}, \mathrm{Al}, \mathrm{Si}) \mathrm{O}_{\mathrm{x}} \mathrm{S}_{\mathrm{y}}$ & + & 39 & & + \\
$(\mathrm{Ti}, \mathrm{Mn}, \mathrm{Si}) \mathrm{O}_{\mathrm{x}} \mathrm{S}_{\mathrm{y}}$ & + & 54 & & + \\
$(\mathrm{Mn}, \mathrm{Si}) \mathrm{O}_{\mathrm{x}} \mathrm{S}_{\mathrm{y}}$ & - & 33,52 & & + \\
$\mathrm{TiN}$ & $\sim$ & & + \\
$(\mathrm{Ti}, \mathrm{Si}) \mathrm{O}_{\mathrm{x}} \mathrm{N}$ & $\sim$ & & + \\
$(\mathrm{Ti}, \mathrm{Mn}, \mathrm{Si}) \mathrm{O}_{\mathrm{x}} \mathrm{N}$ & $\sim$ & - & & + \\
$(\mathrm{Ti}, \mathrm{Mn}) \mathrm{S}_{\mathrm{y}} \mathrm{N}$ & + & - & & + \\
$(\mathrm{Ti}, \mathrm{Mn}, \mathrm{Si}) \mathrm{O}_{\mathrm{x}} \mathrm{S}_{\mathrm{y}} \mathrm{N}$ & $\sim$ & 55 & & + \\
$\mathrm{Al} \mathrm{O}_{3}$ & + & - & & + \\
$(\mathrm{Al}, \mathrm{Mn}) \mathrm{O}_{\mathrm{x}} \mathrm{S}_{\mathrm{y}}$ & $\sim$ & - & & - \\
\hline
\end{tabular}


analysis showed a high potential of these inclusion types for acicular ferrite. Hence, as already shown in Figure 7, an inclusion modification by $\mathrm{MgO}$ did not suppress the acicular ferrite formation.

\section{E. The Role of Ti-Containing Inclusions}

(Ti,Al) $\mathrm{O}_{\mathrm{x}}$ was proved to act as nuclei for acicular ferrite in steel $\mathrm{A} 1$, as illustrated in Figure 16. $(\mathrm{Ti}, \mathrm{Al}) \mathrm{O}_{\mathrm{x}}$ particles were often found as nuclei in heterogeneous inclusions, so only very less-pure $(\mathrm{Ti}, \mathrm{Al}) \mathrm{O}_{\mathrm{x}}$ particles were found in the steels $\mathrm{B}$ and $\mathrm{Cl}$. (Ti, Al) $\mathrm{O}_{\mathrm{x}}$, ( Ti, Mn, Al) $\mathrm{O}_{\mathrm{x}}$, and ( $\left.\mathrm{Ti}, \mathrm{Mn}, \mathrm{Al}\right) \mathrm{O}_{\mathrm{x}} \mathrm{S}_{\mathrm{y}}$ particles were found as major active types in steel $\mathrm{C} 1$, accounting for 45 pct of acicular ferrite nuclei, but their numbers was below $2 \mathrm{~mm}^{-2}$ for each class. Hence, a low number of highly active inclusions can produce the same, or even a higher, amount of acicular ferrite than a large number of moderately effective particles.

The addition of titanium, and the subsequent formation of titanium-containing inclusions, changes the nature of the steel from inactive to highly potent for acicular ferrite. In the present study, steels without titanium were completely inactive for acicular ferrite.

Furthermore, a strong interaction of the inclusion landscape and steel composition is noted. While ( $\mathrm{Ti}, \mathrm{Mn}, \mathrm{Al}) \mathrm{O}_{\mathrm{x}}$ and $(\mathrm{Ti}, \mathrm{Mn}) \mathrm{O}_{\mathrm{x}} \mathrm{S}_{\mathrm{y}}$ inclusions were active in steel $\mathrm{A} 1$ and $\mathrm{C} 1$, they were inactive in steel $\mathrm{B}$.

\section{F. Summary of Observed Inclusion Types}

The inclusion potentials for acicular ferrite in the investigated steel grades are listed in Table IV. The findings are compared with the state of the art in literature. In the table, active inclusions are marked with a plus $(+)$, inert inclusions with a minus ( - , and inclusions that are described as contradictory in the literature with a wavy line $(\sim)$. In steel A1, the oxidic inclusion types: $(\mathrm{Ti}, \mathrm{Mn}) \mathrm{O}_{\mathrm{x}},(\mathrm{Ti}, \mathrm{Al}) \mathrm{O}_{\mathrm{x}}$ and (Ti,Mn, $\mathrm{Al}) \mathrm{O}_{\mathrm{x}}$; the oxysulfidic types: (Ti,Mn) $\mathrm{O}_{\mathrm{x}} \mathrm{S}_{\mathrm{y}}$ and (Ti,Mn,Al) $\mathrm{O}_{\mathrm{x}} \mathrm{S}_{\mathrm{y}}$, as well as $\mathrm{MnS}$ and $(\mathrm{Ti}, \mathrm{Mn}) \mathrm{O}_{\mathrm{x}} \mathrm{S}_{\mathrm{y}} \mathrm{N}$ were found as active particles. Similar inclusion types were determined as potent in steel $\mathrm{Cl}$, in which the oxidic inclusion types: (Ti,Al) $\mathrm{O}_{\mathrm{x}}$ and (Ti, $\left.\mathrm{Mn}, \mathrm{Al}\right) \mathrm{O}_{\mathrm{x}}$, the oxysulfidic types (Ti,Mn) $\mathrm{O}_{\mathrm{x}} \mathrm{S}_{\mathrm{y}}$ and (Ti,Mn,Al) $\mathrm{O}_{\mathrm{x}} \mathrm{S}_{\mathrm{y}}$, as well as MnS were identified as potent nucleation sites. Steel B only showed two types of active inclusions: (Ti, Mn, $\mathrm{Al}) \mathrm{O}_{\mathrm{x}} \mathrm{S}_{\mathrm{y}}$ and $\mathrm{MnS}$.

It is clearly displayed that oxides containing titanium and manganese, as well as $\mathrm{MnS}$, were very effective for acicular ferrite formation. In contrast, alumina- and TiN-rich inclusions were inert. However, small amounts of aluminum in titanium-manganese-oxides did not lower the inclusion's potential.

\section{G. Material Tests}

Three samples of steels C2 and C1 were tested after heat treatment applying the method described in Section II. While C1 showed significant percentages of acicular

Table V. Material Test Data for Investigated Samples

\begin{tabular}{lcccccc}
\hline Sample ID & $d(\mu \mathrm{m})$ & $\mathrm{Rm}(\mathrm{Mpa})$ & $F(N)$ & $\Delta F(N)$ & $\Delta d(\mu \mathrm{m})$ & $\Delta \mathrm{Rm}(\mathrm{Mpa})$ \\
\hline C2-1-01 & 514 & 1217 & 252 & 1 & 5 & \pm 24.18 \\
C2-1-02 & 514 & 1182 & 245 & 1 & 5 & \pm 23.50 \\
C2-1-03 & 514 & 1214 & 252 & 1 & 5 & \pm 24.10 \\
C1-1-01 & 513 & 1062 & 220 & 1 & 5 & 11.86 \\
C1-1-02 & 518 & 1030 & 217 & 1 & 5 & 13.03 \\
C1-1-03 & 506 & 1031 & 207 & 1 & 5 & \pm 2.25 \\
\hline
\end{tabular}
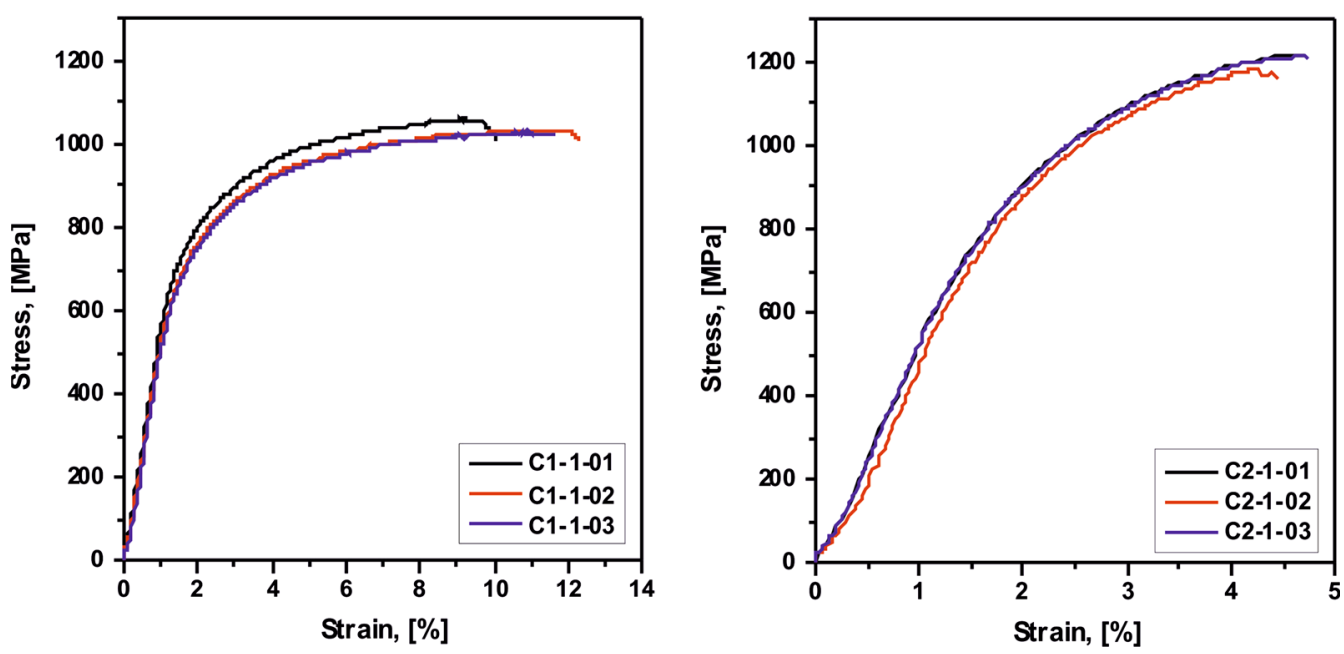

Fig. 17-Stress-strain curves for tested samples C1 (significant percentage of acicular ferritic microstructure) and C2 (bainitic microstructure). 
ferrite in the microstructure, Bainite was predominant in all specimens of C2 (see Section III-A). The tensile test data are summarized in Table V. The obtained stressstrain curves are illustrated in Figure 17. A good reproducibility between the samples was observed. For steel $\mathrm{C} 1$, tensile strength values are lower compared with $\mathrm{C} 2$. However, a remarkable increase of strain values is found in $\mathrm{C} 1$. Also the calculated ductility $\mathrm{Z}$ shows a remarkable increase for samples $\mathrm{C} 1$ compared with $\mathrm{C} 2$. Based on the performed tensile test, values for the fracture toughness cannot be obtained. However, the performed tests were the only accomplishable test due to the very small sample size. Increases in strain and ductility are also seen as indicators for improved fracture toughness.

\section{CONCLUSION}

Non-metallic inclusions are essential for the formation of acicular ferrite. Within this study, the potential of various inclusion types in interaction with the steel composition is evaluated. Samples were melted and heat treated on a laboratory scale. Inclusions were formed by deoxidation and desulfurization of the melt. The main results can be summarized as:

- The carbon content is seen as a crucial precondition for the formation of acicular ferrite. If the carbon content is too high, potential-active inclusion types are also ineffective. Further, solute manganese in the steel matrix proved to be necessary for acicular ferrite formation. The presence of only Mn-containing inclusions in the steel matrix is not sufficient.

- Observed inclusion sizes being active for acicular ferrite formation are in good agreement with the literature. It is shown that on laboratory scale, small (1 to $2 \mu \mathrm{m}$ ECD), effective inclusions can also be realized without the addition of synthetic particle powders.

- Inclusion number should be high enough to provide a sufficient amount of nucleation sites, but as low as possible to fulfill the requirements of high-quality steels. It is clearly demonstrated that the inclusion types' potential for acicular ferrite nucleation was more important than the number of effective particles. Thus, an optimization of the acicular ferrite amount is better performed by changing the inclusion composition than number or size.

- Detected inclusion types might be active in one steel grade, but inactive in another steel grade. The potential for being active for acicular ferrite nucleation has to be always seen and evaluated in close context with the steel composition:

- The effect of $(\mathrm{Ti}, \mathrm{Al}) \mathrm{O}_{\mathrm{x}}$ has been seen controversial in the literature. In the current study, this inclusion type was found as active. Thus, aluminium deoxidation products do not hinder the formation of acicular ferrite, as long as a part of them is modified to active $(\mathrm{Ti}, \mathrm{Al}) \mathrm{O}_{\mathrm{x}}$ inclusions.

- In contrast to many previous studies, single-phase MnS inclusions were also found as potent for acicular ferrite nucleation. MnS was frequently found in the steels A1, $\mathrm{B}$, and $\mathrm{C} 1$ nuclei of acicular ferrite plates.

- MgO-containing inclusions were also found to be active for acicular ferrite. This information could indicate that the use of $\mathrm{MgO}$-containing refractories is innocuous to industrial production of acicular ferritic steels.

- Results of performed tensile tests comparing samples with mostly acicular ferritic and bainitic microstructures underline the high potential of acicular ferritic microstructure to enhance the selected material properties.

\section{ACKNOWLEDGMENTS}

Financial supports by the Federal Ministry for Transport, Innovation and Technology (bmvit) and the Austrian Science Fund (FWF): [TRP 266-N19] are gratefully acknowledged. Microsample (www.microsample.eu) is thanked for performing the tensile tests.

\section{ELECTRONIC SUPPLEMENTARY MATERIAL}

The online version of this article (doi:10.1007/ s11663-017-0984-y) contains supplementary material, which is available to authorized users.

\section{REFERENCES}

1. R. Kiessling and N. Lange: Non-metallic Inclusions in Steel, 2nd ed., Metals Society, London, 1978.

2. R. Kiessling: Metal Science, 1980, vol. 14, pp. 161-72.

3. Y. Murakami: Metal Fatigue: Effects of Small Defects and Nonmetallic Inclusions, 2nd ed., Elsevier, Amsterdam, NL, 2002.

4. J.I. Takamura and S. Mizoguchi: Proc. Int. Iron Steel Congr., 6th, 1990, pp. 591-97.

5. S. Ogibayashi: Nippon Steel Tech Rep, 1994, vol. 61, pp. 70-76.

6. J.M. Gregg and H. Bhadeshia: Acta Mater., 1997, vol. 45, pp. 739 48.

7. K. Wu, Y. Inagawa, and M. Enomoto: Mater. Charact., 2004, vol. 52, pp. 121-27.

8. R.A. Farrar and P.L. Harrison: J Mater Sci, 1987, vol. 22, pp. $3812-20$

9. H.K.D.H. Bhadeshia: Bainite in Steels: Transformations, Microstructure and Properties, 2nd ed., IOM Communications Ltd, London, 2001.

10. D.S. Sarma, A.V. Karasev, and P.G. Jönsson: ISIJ Int., 2009, vol. 49, pp. 1063-74.

11. J.L. Lee and Y.T. Pan: ISIJ Int., 1995, vol. 35, pp. 1027-33.

12. Z. Zhang and R.A. Farrar: Mater. Sci. Technol., 1996, vol. 12, pp. $237-60$.

13. X.L. Wan, H.H. Wang, L. Cheng, and K.M. Wu: Mater. Charact., 2012, vol. 67, pp. 41-51.

14. H. Nako, H. Hatano, Y. Okazaki, K. Yamashita, and M. Otsu: ISIJ Int., 2014, vol. 54, pp. 1690-96.

15. T. Koseki and G. Thewlis: Mater. Sci. Technol., 2005, vol. 21, pp. 867-79.

16. S. Zhang, N. Hattori, M. Enomoto, and T. Tarui: ISIJ Int., 1996, vol. 36, pp. 1301-09.

17. M. Andersson, J. Janis, L. Holappa, M. Kiviö, P. Naveau, M. Brandt, D. Espinosa, L. Bellavia, X. van den Eynde, E. de Courcy, 
L. Chapuis, T. Iung, S. Ekerot and C. van der Eijk: Grain Size Control in Steel by Means of Dispersed Non-Metallic Inclusions-GRAINCONT: Final Report, Publications Office of the European Union, Luxembourg, 2011.

18. S. Hossein Nedjad, Y. Zahedi Moghaddam, A. Mamdouh Vazirabadi, H. Shirazi and M. Nili Ahmadabadi: Mater. Sci. Eng. A, 2011, vol. 528, pp. 1521-26.

19. N. Kikuchi, S. Nabeshima, T. Yamashita, Y. Kishimoto, S. Sridhar, and T. Nagasaka: ISIJ Int., 2011, vol. 51, pp. 2019-28.

20. M. Fattahi, N. Nabhani, M. Hosseini, N. Arabian, and E. Rahimi: Micron, 2013, vol. 45, pp. 107-14.

21. W. Mu, P.G. Jönsson, and K. Nakajima: ISIJ Int., 2014, vol. 54, pp. 2907-16.

22. C. Xuan, W. Mu, Z.I. Olano, P.G. Jönsson, and K. Nakajima: Steel Res. Int., 2016, vol. 87, pp. 911-20.

23. W. Mu, H. Mao, P.G. Jönsson, and K. Nakajima: Steel Res. Int., 2016, vol. 87, pp. 211-19.

24. D. Loder, A. Mayerhofer and S.K. Michelic: Proc. Iron Steel Technol. Conf., 2016, pp. 2465-74.

25. D. You, S.K. Michelic, C. Bernhard, D. Loder, and G. Wieser: ISIJ Int., 2016, vol. 56, pp. 1770-78.

26. D. Loder and S.K. Michelic: Mater. Sci. Technol., 2016, vol. 33, pp. 162-171.

27. D. Loder and S.K. Michelic: Proc. Int. Conf. Clean Steel, 9th, 2015, pp. 1-12.

28. S. Sridhar: Proc. Int. Congr. Sci. Technol. Steelmaking, 3rd, 2005, pp. 797-810.

29. D. Loder, S.K. Michelic, and C. Bernhard: Fortschritte in der Metallographie 46, 1st ed., Werkstoff Informationsgesellschaft, Frankfurt, DE, 2014, pp. 125-130.

30. S. Burgess: Proc. of Conf. on Non-metallic Inclusion Control and Continuous Improvement of Processes Based on Objective Measurement, vol. 2004, paper 17, pp. 1-15.

31. M. Nuspl, W. Wegscheider, J. Angeli, W. Posch, and M. Mayr: Anal. Bioanal. Chem., 2004, vol. 379, pp. 640-45.

32. G. Rathmayr, A. Bachmaier, and R. Pippan: J. Test. Eval., 2013, vol. 41, pp. 635-46.

33. K. Seo, Y.M. Kim, G.M. Evans, H.J. Kim, and C. Lee: Weld. World, 2015, vol. 59, pp. 373-80.

34. T.K. Lee, H.J. Kim, B.Y. Kang, and S.K. Hwang: ISIJ International, 2000, vol. 40, pp. 1260-68.
35. S.J. Luo, Y.H. Frank Su, M.J. Lu, and J.C. Kuo: Mater. Charact., 2013, vol. 82, pp. 103-12.

36. W. Mu, P.G. Jönsson and K. Nakajima: Proc. Int. Congr. Sci. Technol. Steelmaking, 6th, 2015, pp. 767-71.

37. R.A. Ricks, P.R. Howell, and G.S. Barritte: J. Mater. Sci., 1982, vol. 17, pp. 732-40.

38. R. Ricks, G. Barritte and P. Howell: Proc. Int. Conf. Solid-Solid Phase Transform., 1981, pp. 463-68.

39. F.J. Barbaro, P. Krauklis, and K.E. Easterling: Mater. Sci. Technol., 1989, vol. 5, pp. 1057-68.

40. Q. Huang, X. Wang, M. Jiang, Z. Hu, and C. Yang: Steel Res. Int., 2016, vol. 87, pp. 445-55.

41. M.M. Song, B. Song, C.L. Hu, W.B. Xin, and G.Y. Song: ISIJ Int., 2015, vol. 55, pp. 1468-73.

42. X. Wang, Z. Hu, M. Jiang, W. Wang, C. Yang and S. Li: Proc. Int. Congr. Sci. Technol. Steelmaking, 5th, 2012, pp. 1-10.

43. J.H. Shim, Y.W. Cho, J.D. Shim, Y.J. Oh, J.S. Byun, and D.N. Lee: Metall. Mater. Trans. A, 2001, vol. 32, pp. 75-83.

44. A.G. Fox and G.M. Evans: Trends Weld. Res., Proc. Int. Conf., 5th, 2012, pp. 1-9.

45. C. Zheng, X. Wang, S. Li, C. Shang, and X. He: Sci. China: Technol. Sci., 2012, vol. 55, pp. 1556-65.

46. R.A. Farrar and P.L. Harrison: J. Mater. Sci., 1987, vol. 22, p. 3820 .

47. G.M. Evans: Am. Weld. Soc. J. Suppl., 1980, pp. 67-75.

48. F. Chai, H. Su, C.F. Yang, and D.M. Xue: J. Iron Steel Res. Int., 2014, vol. 21, pp. 369-74.

49. Z. Zhang and R.A. Farrar: Mater. Sci. Technol., 1996, vol. 12, pp. $237-70$

50. J.H. Shim, Y.J. Oh, J.Y. Suh, Y.W. Cho, J.D. Shim, J.S. Byin, and D.N. Lee: Acta Mater., 2001, vol. 49, pp. 2115-22.

51. M.N. Ilman, R.C. Cochrane, and G.M. Evans: Weld. World, 2015, vol. 59, pp. 565-75.

52. J.S. Byun, J.H. Shim, Y.W. Cho, and D.N. Lee: Acta Mater., 2003, vol. 51, pp. 1593-606.

53. Z. Cai, Y. Zhou, L. Tong, Q. Yue, and H. Kong: Mater. Process., 2015, vol. 57, pp. 649-54.

54. K. Hui, S. YunFu, Z. YaHui, Y. Qiang, T. Lianhai, and C. ZhengYu: Mater. Process., 2014, vol. 56, pp. 131-35.

55. H.H. Jin, J.H. Shim, Y.W. Cho, and H.C. Lee: ISIJ Int., 2003, vol. 43 , pp. 1111-13. 